Article

\title{
The Effect of Plant-Derived Biostimulants on White Head Cabbage Seedlings Grown under Controlled Conditions
}

\author{
Katarzyna Godlewska ${ }^{1, * \mathbb{D}}$, Anita Biesiada ${ }^{1}$, Izabela Michalak ${ }^{2} \mathbb{D}$ and Paweł Pacyga ${ }^{3}$ \\ 1 Department of Horticulture, The Faculty of Life Science and Technology, Wrocław University of \\ Environmental and Life Sciences, Grunwaldzki 24A, 50-363 Wrocław, Poland; anita.biesiada@upwr.edu.pl \\ 2 Department of Advanced Material Technologies, Faculty of Chemistry, Wrocław University of Science and \\ Technology, Smoluchowskiego 25, 50-372 Wrocław, Poland; izabela.michalak@pwr.edu.pl \\ 3 Department of Design Fundamentals and Fluid-Flow Machinery, Faculty of Mechanical and Power \\ Engineering, Wrocław University of Science and Technology, Na Grobli 15, 50-421 Wrocław, Poland; \\ pawel.pacyga@pwr.edu.pl \\ * Correspondence: katarzyna.godlewska@upwr.edu.pl
}

Received: 2 September 2019; Accepted: 23 September 2019; Published: 26 September 2019

\begin{abstract}
The aim of this study was to investigate the potential of using natural raw materials that have not been used for the production of biostimulants of plant growth. These products can effectively contribute to overcome the challenge posed by the increasing demand for food. Ultrasound assisted extraction (UAE) was chosen to prepare innovative biostimulants. The expected outcome of this research was to generate products that show beneficial effects on white head cabbage growth, development, and nutritional quality. The results proved that higher plants (mugwort, calendula, purple coneflower, chamomile, basil, giant goldenrod, comfrey, dandelion, and valerian) can be successfully used for the production of biostimulants. For example, products based on common dandelion showed the highest biostimulating activity. In a group treated with $2.5 \%$ flower extract, cabbage shoots were $37 \%$ longer, whereas in a group treated with $0.5 \%$ leaves extract, roots were longer by $76 \%$ as compared with a control group treated with water. Biostimulants based on common mugwort (at a dose of $0.5 \%$ ) and common dandelion (root) (at a dose of 1.0\%) increased the mass of cabbage shoots and roots by $106 \%$ and $246 \%$, respectively. The majority of biostimulants increased the content of photosynthetic pigments (chlorophyll and carotenoids) and decreased the content of polyphenols. Botanical extracts also showed varied impact on the antioxidant activity of cabbage. Taking into account the benefits for a wide scope of applications, it is expected that the utilization of these types of products should increase in the future. These products can play a key role in sustainable agriculture.
\end{abstract}

Keywords: biostimulants of plant growth; higher plants; extraction; ultrasounds; white head cabbage seedlings; foliar spray

\section{Introduction}

Currently, in agriculture (horticulture), there is a lot of interest in natural products that will increase the yield and simultaneously the biological value of the cultivated plants, without negative effects on the natural environment. Such innovative products are biostimulants of plant growth which can be successfully applied in sustainable agriculture. To be recognized as a biostimulant of plant growth, a product should modify the plant physiology. This action causes plants to more efficiently use the limited resources of the environment (e.g., water) and protects plants from harmful agents induced by stressful conditions or pathogens. Biostimulants of plant growth do not supply 
appropriate amounts of essential nutrients to plants, but they enhance their uptake by the root system, and they increase the growth of a plant subjected to stress due to increased antioxidant activity [1,2]. Currently, several groups of biostimulants of plant growth are distinguished which include extracts from seaweeds and botanicals, humic and fulvic acids, hydrolysates protein, other nitrogen-containing compounds, beneficial bacteria and fungi, chitosan and other biopolymers, and inorganic compounds [2,3]. In this study we have focused on the production of biostimulants from higher plants. As a raw material, we selected plant biomass that is easily available and known for unique properties, i.e., mugwort (Artemisia vulgaris L.), calendula (Calendula officinalis), purple coneflower (Echinacea purpurea), chamomile (Matricaria chamomilla), basil (Ocimum basilicum L.), giant goldenrod (Solidago gigantean), comfrey (Symphytum officinale), dandelion (Taraxacum officinale), and valerian (Valeriana officinalis).

These plants are a rich source of bioactive compounds which can stimulate plant growth. Sytar et al. (2018) [4] showed that methanolic extracts from plants that belong to the Asteraceae family contained phenolics and flavonoids and that they demonstrated good antioxidant activity. In more detail, for example Echinacea purpurea can serve as a source of polysaccharides, volatile oils, flavonoids, anthocyanins, free phenolic acids, betaine, fatty acids, simple sugars, and sterols [5]. Artemisia vulgaris leaves can act as a source of phenolic compound with antioxidant properties [6]. Another representative of the Asteraceae family, Calendula officinalis, is globally known for its content of phytochemicals including lipids, fatty acids, amino acids, carotenoids, carbohydrates, quinones, terpenoids, flavonoids, coumarins, and other constituents [7].

Biostimulants of plant growth are usually applied as liquids in the form of natural extracts. In order to isolate biologically active compounds from plant biomass, different extraction techniques can be used. In this study, we proposed ultrasound assisted extraction (UAE) with water as a solvent, since the extracts were used in plant cultivation. The main advantages of this technique are low volumes of solvents used, faster kinetics (in the first few minutes, the highest extraction rate is usually achieved), extraction of heat-sensitive compounds without damage, and increased extraction yield [6-9]. This technology not only focuses on the disruption of the material, but also addresses environmental aspects such as cross-contamination, noise, and possible infections, etc. This method belongs to the group of novel extraction techniques which include, in addition to UAE, microwave assisted extraction (MAE), supercritical fluid extraction (SFE), and enzyme assisted extraction (EAE) [8].

All products used in the cultivation of horticultural plant should be easy to use, effective at low doses, safe for plants and the environment, and nontoxic to other organisms [10]. Melguizo-Melguizo et al. (2014) [6] showed that the maceration and ultrasound assisted extraction of Artemisia vulgaris using methanol and acetone produced extracts rich in polyphenols with very good antioxidant properties. Other researchers also used water as a solvent to prepare biostimulants of plant growth, for example, garlic extract obtained by homogenization [11], oak extract obtained by the maceration in water [12], and extracts from representatives of the Asteraceae family achieved by the heating of the biomass in water for $15 \mathrm{~min}$ at $95^{\circ} \mathrm{C}$ [4]. Merwad (2018) [13] applied homogenization of Moringa oleifera in ethanol, but the final diluted solutions of biostimulants were prepared in water.

The obtained plant extracts contain plant growth promoting substances, such as polyphenols and phytohormones [14], amino acids, vitamins [15], nutrients, micro- and macroelements, betaines, and mannitol [16]. Moreover, plant extracts facilitate the absorption of micro- and macroelements from soil, as well as their transport and distribution in the plant [15]. Therefore, they have a positive effect on the cultivated plants, which has been confirmed in the literature. For example, plant biostimulants were shown to increase growth (shoot length and leaf area) and potassium uptake in almond [16]. Ertani et al. (2016) [14] reported that vegetal extracts derived from blueberry fruits, red grape, and hawthorn leaves increased the biomass of roots and leaves, as well as the content of chlorophyll and sugars in maize. The application of natural biostimulants resulted in the increase of pigment, vitamin C, and total phenolics content of paper leaves, as well as the plant yield [15]. Garlic aqueous extract revealed stimulatory activity on the growth (plant height, number of leaves, 
root growth, fresh and dry weight) and the content of plant metabolites such as soluble sugars, pigments, chlorophyll, and carotenoids in the biomass of eggplant and pepper [11]. In the work of Merwad (2018) [13], aqueous extract from Moringa oleifera enhanced the growth, yield, content of the photosynthetic pigments, proteins, and nutrients in pea plants.

On the basis of presented examples, we predict that the use of biostimulants in agriculture will become a common practice [16]. Moreover, biostimulants can be treated as a new generation of products for sustainable agriculture and slowly can become an alternative to synthetic products [11]. Additionally, biostimulants can help in the reduction of fertilizers application and, consequently, can reduce environmental pollution [15]. It should also be emphasized that a lot of research is still needed concerning the production of new biostimulants from available raw materials, as well as determination of their mode of action. The full mechanism of the biological activity of biostimulants of plant growth is still unknown.

In many studies, commercially available plant biostimulants are tested. The aim of our research was to produce new and natural biostimulants of plant growth from the following higher plants: Mugwort (Artemisia vulgaris L.), calendula (Calendula officinalis), purple coneflower (Echinacea purpurea), chamomile (Matricaria chamomilla), basil (Ocimum basilicum L.), giant goldenrod (Solidago gigantean), comfrey (Symphytum officinale), dandelion (Taraxacum officinale), and valerian (Valeriana officinalis), and to examine their properties in germination tests on white head cabbage. We present, for the first time, a comprehensive approach which involved the selection of raw material through the ultrasound assisted extraction of nine plant biomasses and the examination of the effect of obtained plant extracts on the growth and biological value of cabbage. Special attention was paid to the plant yield and the content of pigments in cabbage leaves and their antioxidant properties.

\section{Materials and Methods}

\subsection{Chemicals}

Acetone, calcium carbonate, sodium carbonate, ethanol, methanol, potassium persulphate, acetic acid, and sodium acetate were purchased from IDALIA (Radom, Poland). Folin-Ciocalteu's phenol reagent, Trolox, gallic acid, diphenyl-2-picrylhydrazyl (DPPH), azino-bis-3-ethylbenzthiazoline6-sulphonic acid (ABTS), ferric reducing antioxidant power (FRAP), and tripyridyl-S-triazine (TPTZ) were purchased from Archem (Lany, Poland). The used reagents were of analytical grade.

\subsection{Plant Materials}

Selected raw materials that were used in this study are common plants in Poland, containing large amounts of compounds with potential biostimulant effects. The time of the biomass collection depended on the plant part used for the extraction. The level of biologically active constituents can vary in different parts of plant species that are at different stages of the plant growth and development [17]. In addition, climatic and environmental conditions (e.g., rainfall, light, and temperature) can affect the chemical composition of selected plants. Higher plants were harvested once, in 2017, in Wrocław. The biostimulatory potential was studied for the following biomasses: Artemisia vulgaris L. (herb) $(\mathrm{Av} \mathrm{H})$, Calendula officinalis (flower) (Co F), Echinacea purpurea (flower, leaf) (Ep F, Ep L), Matricaria chamomilla (flower) (Mc F), Ocimum basilicum L. (herb) (Ob H), Solidago gigantea (leaf) (Sg L), Symphytum officinale (root) (So R), Taraxacum officinale (flower, leaf, root) (To F, To L, To R), and Valeriana officinalis (root) (Vo R). The raw materials were adequately prepared (dried at $50{ }^{\circ} \mathrm{C}$, grinded to a mesh size of $500 \mu \mathrm{m}$, and averaged) to obtain the most representative samples for further analysis. Samples were appropriately stored at room temperature in special stringed bags.

\subsection{Extracts Production}

Ultrasound assisted extraction is a promising method to extract high levels of valuable bioactive compounds from a wide range of biomasses. UAE enhances the extraction yield and simultaneously reduces the use of solvents in contradistinction to the conventional extraction techniques. 
In addition, it gives the ability to use greener alternative solvents, and to increase the extraction of temperature-sensitive components [18]. Extracts from higher plants were produced according to the modified procedure described by Maran et al. (2017) [19]. The dried and milled biomasses of higher plants were mixed with deionized water in the ratio 1:20, well stirred, and left for $30 \mathrm{~min}$ at room temperature $\left(23 \pm 2{ }^{\circ} \mathrm{C}\right)$. Subsequently, ultrasounds $(50 \mathrm{~W}, 30 \mathrm{~min})$ were applied to carry out the cell disruption (homogenizer UP $50 \mathrm{H}$; Hielscher Ultrasonics $\mathrm{GmbH}$, Teltow, Germany). After extraction, mixtures were centrifuged at $4500 \mathrm{rpm}$ for $10 \mathrm{~min}$ (Heraeus Megafuge 40, rotor TX-750, Thermo Scientific, Waltham, MA, USA). The obtained supernatants were collected and taken as a $100 \%$ liquid extract and stored in a dark glass container in the refrigerator until further analyses.

\subsection{Utilitarian Properties of Extracts}

In order to verify if biostimulants based on higher plant biomasses improve quantitative and qualitative parameters of plants, germination tests on cabbage were performed under controlled conditions. This approach allowed us to define the best application methods, timing and doses, and provided preliminary indications of phytotoxicity. The schematic methodology is presented in Figure 1.

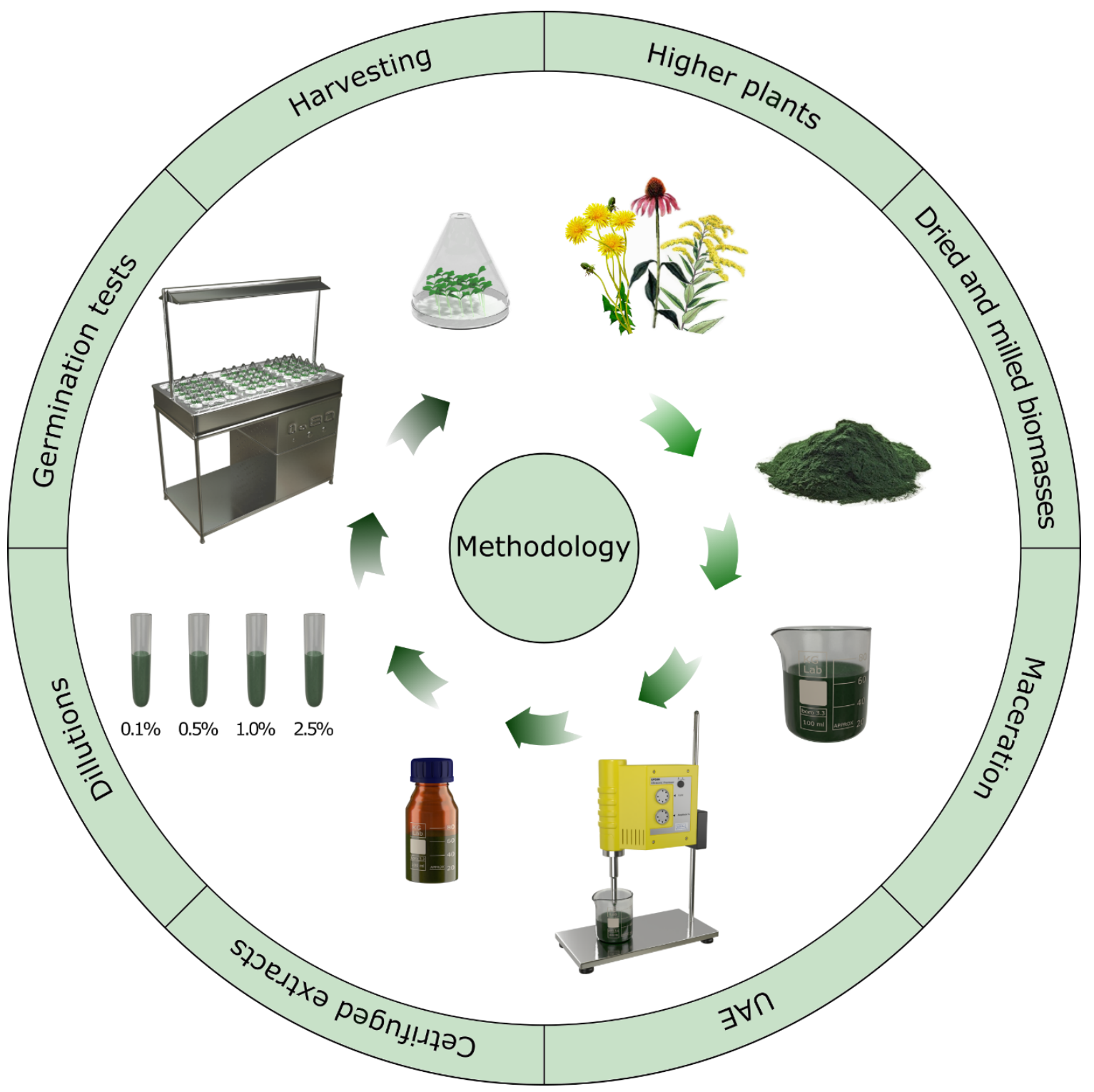

Figure 1. The schematic methodology of experiments. 


\subsubsection{Germination Tests}

The phytotoxicity of the produced extracts was assessed in the germination tests on white head cabbage (variety 'Socrates', Syngenta, Poland). The effects of different concentrations $(0.1 \%, 0.5 \%$, $1.0 \%$, and $2.5 \%$ ) of the extracts on plant growth were tested. The dilutions of extracts were determined in the previous work of [20]. Experiments were conducted on Petri dishes, in 8 replicates for each group in standardized conditions $\left(25 / 20^{\circ} \mathrm{C}\right.$ day/night temperature, $5000 \mathrm{lux}, 14 / 10 \mathrm{~h}$ light/dark period, $70 \%$ to $80 \%$ relative humidity) using Jacobsen apparatus (Laborset, Lodz, Poland) according to the international norm (International Rules for Seed Testing, 2011, International Seed Testing Association (Bassersdorf, Switzerland)). The experiment was laid out in a completely randomized design. On each Petri dish (diameter $90 \mathrm{~mm}$ ), 25 seeds were placed on the moistened filter paper. The filter paper was controlled and repeatedly watered with deionized water in order to avoid excessive drying. After six days of germination, at the phase of developed cotyledons, seedlings were sprayed with $1 \mathrm{~mL}$ of produced extracts, whereas control groups were treated with commercial biostimulant (CB) or deionized water $(\mathrm{C})$. On the eighth and tenth day, all Petri dishes were sprayed with the same doses of biostimulants or water. After fourteen days, cultivated seedlings were collected, the length of shoots and roots were measured, weighed, and subjected to further analyses.

\subsubsection{The Pigments Concentration and Greenness Index of the Leaf}

The chlorophyll $a+b$ and carotenoids in leaves of cabbage seedlings were established using UV-VIS spectrophotometer (Varian Cary 50 Conc. Instrument, Victoria, Australia). Extractions were made in $80 \mathrm{mg} \cdot \mathrm{mL}^{-1}$ acetone [21]. The appropriate amounts of samples $(0.2 \mathrm{~g})$ were ground up with a mortar and pestle, along with a few drops of acetone and pinch of sand and calcium carbonate. Then, filtered (using Schott filter and vacuum pump) and quantitatively transferred to the measuring flask and filled up to $50 \mathrm{~mL}$ with acetone. The absorbance was immediately measured at the following wavelengths: 663,645 , and $470 \mathrm{~nm}$. Analysis were done in three replicates. The concentrations of chlorophyll $a+b$ (mg.100 $\mathrm{g}^{-1}$ fresh weight, FW) and carotenoids ( $\left.\mu \mathrm{g} \cdot 100 \mathrm{~g}^{-1} \mathrm{FW}\right)$ were determined from the equations given below:

$$
\begin{gathered}
\text { Chlorophyll } \mathrm{a}=\left(\frac{12.7 \cdot A_{663}-2.69 \cdot A_{645}}{20 \cdot w}\right) \cdot 100 \\
\text { Chlorophyll } \mathrm{b}=\left(\frac{22.9 \cdot A_{645}-4.68 \cdot A_{663}}{20 \cdot w}\right) \cdot 100 \\
\text { Carotenoids }=\left(\frac{1000 \cdot A_{470}-3.27 \cdot \text { Chlorophyll a }-104 \cdot \text { Chlorophyll b }}{22.9}\right) \cdot 100
\end{gathered}
$$

where $A$ is absorbance $(\mathrm{nm})$ and $w$ is weight of fresh plant material (g).

The greenness index of the leaves was measured using a chlorophyll meter SPAD 502 Plus (Konica Minolta, Japan). From each Petri dish, 5 leaves were selected and the index was measured in three replicates.

\subsubsection{The Concentration of Polyphenols}

The content of total phenolic compounds (TPC) in cabbage shoots was measured according to the Folin-Ciocalteu method described by Jałoszyński et al. (2008) [22] with slight modifications. To determine TPC, fresh biomasses of harvested plants were ground and $2 \mathrm{~g}$ were added to $20 \mathrm{~mL}$ of $80 \mathrm{mg} \cdot \mathrm{mL}^{-1}$ aqueous methanol, and the suspension was slightly stirred. The test tubes were sonicated for $15 \mathrm{~min}$ and centrifuged $(10 \mathrm{~min}, 4500 \mathrm{rpm})$. The obtained supernatants $(0.1 \mathrm{~mL})$ were mixed with Folin-Ciocalteu's phenol reagent $(0.2 \mathrm{~mL})$, distilled water $(2.0 \mathrm{~mL})$, and incubated at room temperature for $3 \mathrm{~min}$. Afterwards, $20 \mathrm{mg} \cdot \mathrm{mL}^{-1}$ sodium carbonate $(1.0 \mathrm{~mL})$ was added, and the reaction mixtures were incubated for $1 \mathrm{~h}$ in the dark. The absorbance of the resulting blue color was determined at $765 \mathrm{~nm}$ with a spectrophotometer (Varian Cary 50 Conc. Instrument, Victoria, Australia). Quantification was 
done with reference to the standard curve of gallic acid $\left(\mathrm{C}=23.35 \cdot \mathrm{A}-1.675, R^{2}=0.992\right)$. The results were expressed as gallic acid equivalents (GAE), milligrams per $100 \mathrm{~g} F W$. All determinations were performed in triplicates.

\subsubsection{The Antioxidant Activity (DPPH, ABTS, and FRAP)}

The DPPH radical scavenging activity was established using the method suggested by Yen and Chen (1995) [23] with slight modifications. The radical stock solution of DPPH, prepared fresh daily, was dissolved in $96 \mathrm{mg} \cdot \mathrm{mL}^{-1}$ ethanol. Ten-fold diluted supernatants $(0.5 \mathrm{~mL})$ were mixed with ethanol $(1.5 \mathrm{~mL})$ and DPPH solution $(0.5 \mathrm{~mL})$. The mixtures were shaken vigorously and allowed to stand at room temperature in the dark for $10 \mathrm{~min}$. The decrease in absorbance was measured at $517 \mathrm{~nm}$. The results were expressed in $\mu \mathrm{M}$ Trolox per $1 \mathrm{~g}$ FW.

The procedure of ABTS assay was followed by the modified method of Re et al. (1999) [24] and Almeida et al. (2011) [25]. The ABTS radical cation was prepared by reaction of aqueous ABTS solution $(5 \mathrm{~mL}, 7 \mathrm{mM})$ with potassium persulfate solution $(88 \mu \mathrm{L}, 140 \mathrm{mM})$. The mixture was held in the dark at $29^{\circ} \mathrm{C}$ for at least $14 \mathrm{~h}$ and diluted with ethanol in order to obtain an absorbance of $0.7 \pm 0.02$ units at $734 \mathrm{~nm}$ before being used. Plant extracts $(30 \mu \mathrm{L})$ were allowed to react with $3 \mathrm{~mL}$ of blue-green ABTS solution in the dark condition for 6 min. The results were expressed in $\mu \mathrm{M}$ Trolox per $1 \mathrm{~g} F W$.

The FRAP antioxidant capacity was estimated spectrophotometrically following the modified procedure of Benzie and Strain (1996) [26]. The ferric reducing antioxidant power (FRAP) reagent was prepared by mixing acetate buffer $(300 \mathrm{mM})$, TPTZ $(10 \mathrm{~mL}$ in $40 \mathrm{mM} \mathrm{HCl})$ and $\mathrm{FeCl}_{3} \cdot 6 \mathrm{H}_{2} \mathrm{O}(20 \mathrm{mM})$ in a ratio of 10:1:1 at $37^{\circ} \mathrm{C}$. Freshly prepared solution $(3 \mathrm{~mL})$ was added to extracts $(1 \mathrm{~mL})$ and after $10 \mathrm{~min}$ the absorbance at $593 \mathrm{~nm}$ was measured. The FRAP values were obtained by comparing the change in absorbance and expressed in $\mu \mathrm{M}$ Trolox per $1 \mathrm{~g}$ FW. All determinations were performed in triplicates.

\subsection{Statistical Analysis}

The results were devised statistically by Statistica version 13.1 (StatSoft Polska Sp. z o.o., Kraków, Poland). Normality of distribution was evaluated by the Shapiro-Wilk test. For normal distribution, the homogeneity of variance was assessed using the Brown-Forsythe test, and the differences were estimated with the (HSD) Tukey test (the comparison of all pairs of means following one-way ANOVA). Results were considered significantly different when $p<0.05$. For distribution other than normal, the Kruskal-Wallis test was used. Statistically significant differences between applied extracts and water were marked with " $a$ " and between commercial products with " $b$ ".

\section{Results}

The conducted study demonstrated a significant impact of the tested botanical extracts after foliar application on cabbage seedlings growth and development.

\subsection{The Effect of Extracts on the Length of Shoots}

The obtained extracts showed a differential level of stimulant effect on plant growth (Figure 2). The least biostimulating effect on the length of cabbage shoots showed products obtained from Echinacea purpurea, both flower and leaf. For example, in the group treated with $0.1 \%$ solution, plants were shorter by $31.7 \%$ and $20.2 \%$ in comparison with C, respectively. The reduction of plant growth (by $5.7 \%$ ) was also noted in the group treated with a commercial biostimulant as compared to $\mathrm{C}$, but this difference was not statistically significant. Other plant extracts mostly had a favorable effect on the shoot length. The longest plants were in groups treated with the following: $0.1 \%$ and $0.5 \% \mathrm{Av} \mathrm{H}(32.1 \%$ and $27.9 \%$ longer than in $\mathrm{C}$ and $40.1 \%$ and $35.6 \%$ longer than in CB), $2.5 \%$ So $\mathrm{R}(26.3 \%$ and $34.0 \%$ longer than in $\mathrm{C}$ and $\mathrm{CB}$, respectively), $1.0 \%$ and $2.5 \%$ To $\mathrm{F}$ ( $27.5 \%$ and $37.0 \%$ longer than in $\mathrm{C}$ and $35.2 \%$ and $45.3 \%$ longer than in $\mathrm{CB})$, and $0.1 \%$ To $\mathrm{R}(30.5 \%$ and $38.5 \%$ longer than in $\mathrm{C}$ and $\mathrm{CB}$, respectively). 


\subsection{The Effect of Extracts on the Length of the Roots}

The use of biostimulants also caused the stimulation of the root system growth (Figure 3 ). The longest roots were observed after application of $0.5 \%$ Vo $R(77.0 \%$ and $80.3 \%$ longer than in $C$ and $C B$, respectively), $0.1 \% \mathrm{Sg} \mathrm{L}$ (75.6\% and $78.9 \%$ longer than in C and CB), and $0.5 \%$ To L (77.5\% and 80.8\% longer than in $\mathrm{C}$ and $\mathrm{CB}$ ). As in the case of the length of the above ground biomass, extracts based on Ep F and Ep L did not stimulate the growth of roots. Also 2.5\% extract of To F did not increase the length of roots significantly (only by $1.2 \%$ and $3.0 \%$ as compared with $\mathrm{C}$ and $\mathrm{CB}$, respectively).

\subsection{The Effect of Extracts on the Fresh Weight of Shoots}

The germination tests indicated that the application of botanical biostimulants significantly increased the fresh weight of shoots (Figure 4). For example, all concentrations of Av $\mathrm{H}$ increased the weight in the range $67.1-105.9 \%$ in comparison with $C$, and by $73.2-113.4 \%$ when compared to CB. In the group treated with $0.5 \%$ To F, plants were heavier by $91.8 \%$ and $98.8 \%$ than in $\mathrm{C}$ and $\mathrm{CB}$, respectively. In general, the application of extracts based on Mc F did not show statistically significant biostimulating activity.

\subsection{The Effect of Extracts on the Fresh Weight of Roots}

Results of the germination tests indicated a significant increase in the fresh weight of roots after the foliar application of most biostimulants (Figure 5). The highest impact on roots was attained after application of the following extracts: $0.5 \%$ Av $\mathrm{H}$ (heavier by $192.3 \%$ and $100.0 \%$ in comparison with C and $\mathrm{CB}$, respectively), $0.5 \%$ Vo $\mathrm{R}$ (heavier by $215.4 \%$ and $115.8 \%$ than in C and CB), $2.5 \%$ To $\mathrm{L}$ (heavier by $223.1 \%$ and $121.1 \%$ than in $C$ and CB), and $1.0 \%$ To $R$ (heavier by $246.2 \%$ and $136.8 \%$ than in $C$ and $\mathrm{CB})$. The lightest roots were in the group treated with Ep F (0.0-23.1\% heavier than C and 31.6-15.8\% lighter than $\mathrm{CB}$ ).

\subsection{The Effect of Extracts on the Dry Weight of Shoots}

Produced botanical biostimulants showed a positive effect on the dry weight of cabbage shoots (Figure 6). Extracts based on Av $\mathrm{H}$ increased the dry weight in the range of 54.1-65.5\% in comparison with C, and by $54.9-66.4 \%$ in comparison with CB. Moreover, To F stimulated the weight of shoots, which in this group were heavier by $44.1 \%$ to $60.7 \%$ than in C, and by $44.9 \%$ to $61.6 \%$ than in CB. The least stimulating effect was observed after application of Mc F extracts.

\subsection{The Effect of Extracts on the Dry Weight of Roots}

Botanical extracts increased dry weight of roots (Figure 7). The highest dry weight of roots was achieved after application of $0.5 \%$ Vo $\mathrm{R}$ and $1.0 \%$ To $\mathrm{R}(53.3 \%$ and $33.3 \%$ more than in $\mathrm{C}$ and $\mathrm{CB}$ ), and $2.5 \%$ To L (54.5\% and 34.3\% more than in C and CB). The lightest roots were in groups treated with Ep $\mathrm{F}(1.7 \%$ to $5 \%$ more than $\mathrm{C}$ and $8.7 \%$ to $11.6 \%$ less than $\mathrm{CB})$.

\subsection{The Effect of Extracts on the Content of Chlorophyll and Carotenoids, and the Greenness Index of Leaf (SPAD)}

Biostimulants often increase the content of chlorophyll which is pigment that is crucial for the proper course of photosynthesis. This was also confirmed in the present study (Figure 8). Produced extracts had a significant impact on the increase in chlorophyll content, for example, $0.1 \% \mathrm{Mc} F$ increased the content of this pigment by $111.5 \%$ or $0.5 \%$ To L by $109.6 \%$ in comparison with C. These extracts did not show the statistically significant differences when compared to CB. The lowest biostimulating activity showed the extract $0.1 \%$ Co F, in this group plants, contained less chlorophyll by $9.5 \%$ in comparison with $\mathrm{C}$ and by $56.9 \%$ in comparison with $\mathrm{CB}$. 


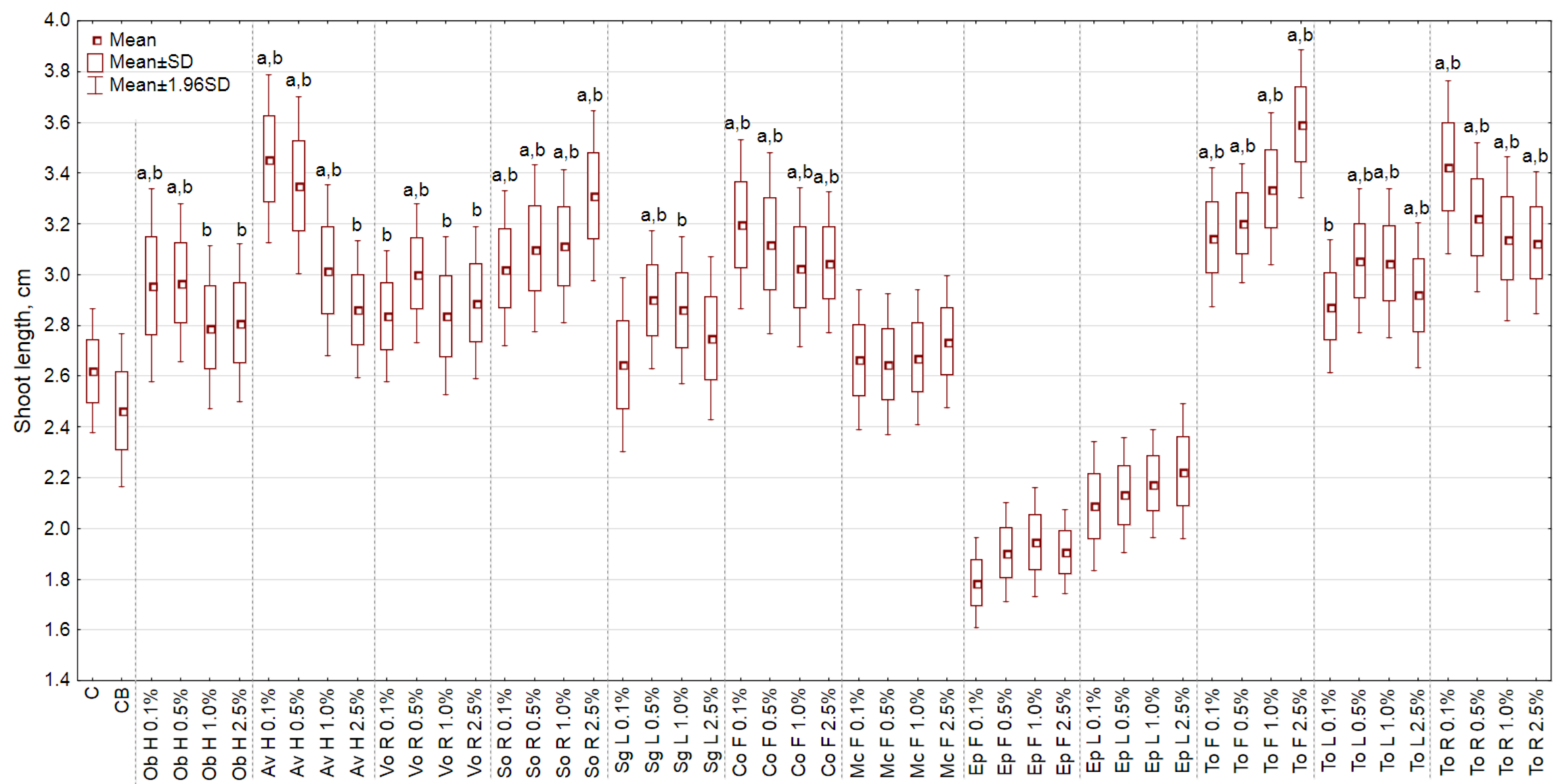

Figure 2. The effect of extracts on the shoot length of white head cabbage seedlings. (a) Statistically significant differences $(p<0.05)$ between control group (C) and extracts. (b) Statistically significant differences $(p<0.05)$ between commercial biostimulant (CB) and extracts. Abbreviations: Av H, Artemisia vulgaris L. (herb); Co F, Calendula officinalis (flower); Ep F, Ep L, Echinacea purpurea (flower, leaf); Mc F, Matricaria chamomilla (flower); Ob H, Ocimum basilicum L. (herb); Sg L, Solidago gigantea (leaf); So R, Symphytum officinale (root); To F, To L, To R, Taraxacum officinale (flower, leaf, root); and Vo R, Valeriana officinalis (root). 


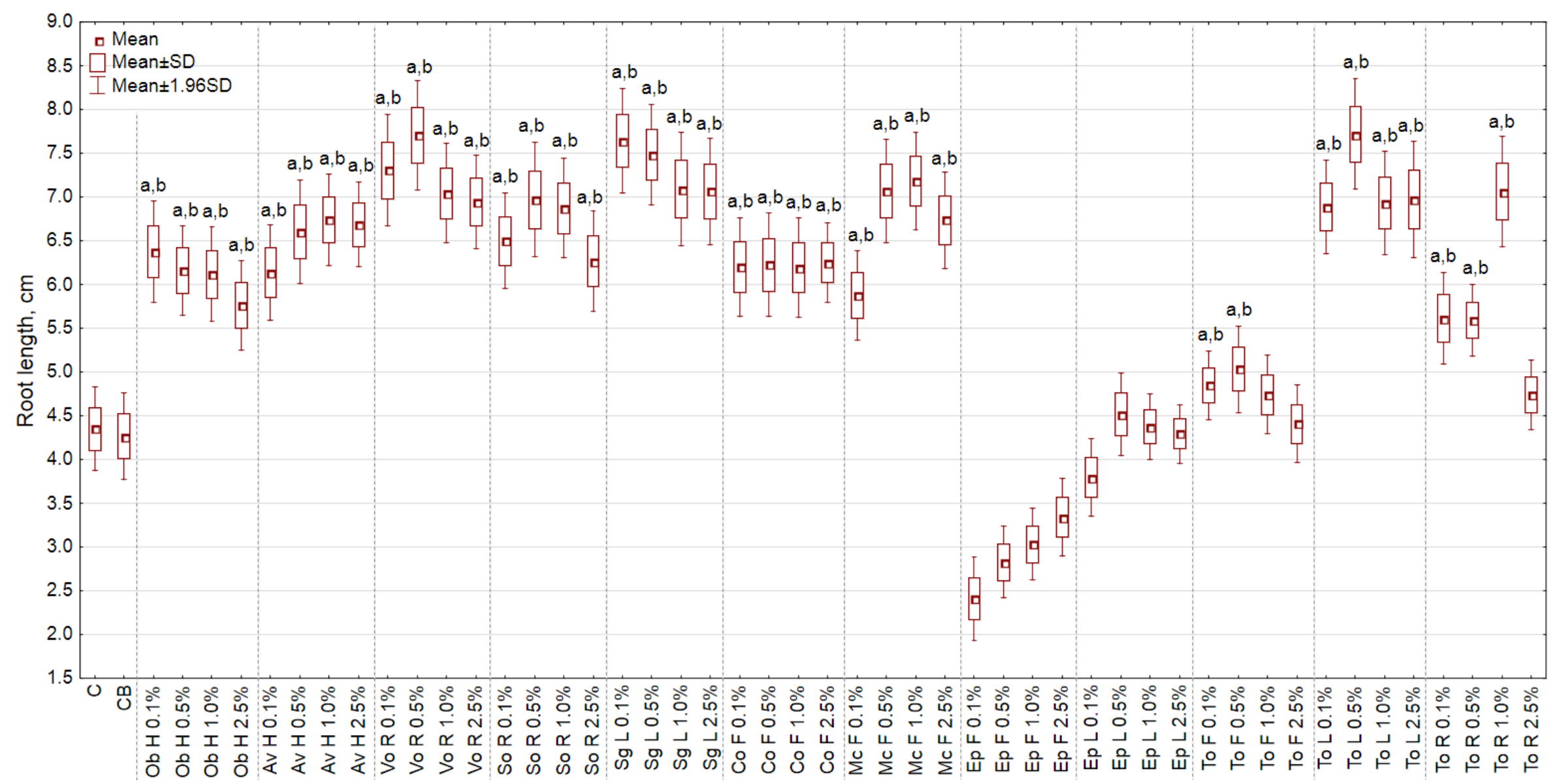

Figure 3. The effect of extracts on the length of the roots of white head cabbage seedlings. (a) Statistically significant differences $(p<0.05)$ between control group (C) and extracts. (b) Statistically significant differences $(p<0.05)$ between commercial biostimulant $(\mathrm{CB})$ and extracts. Abbreviations as in Figure 2 . 


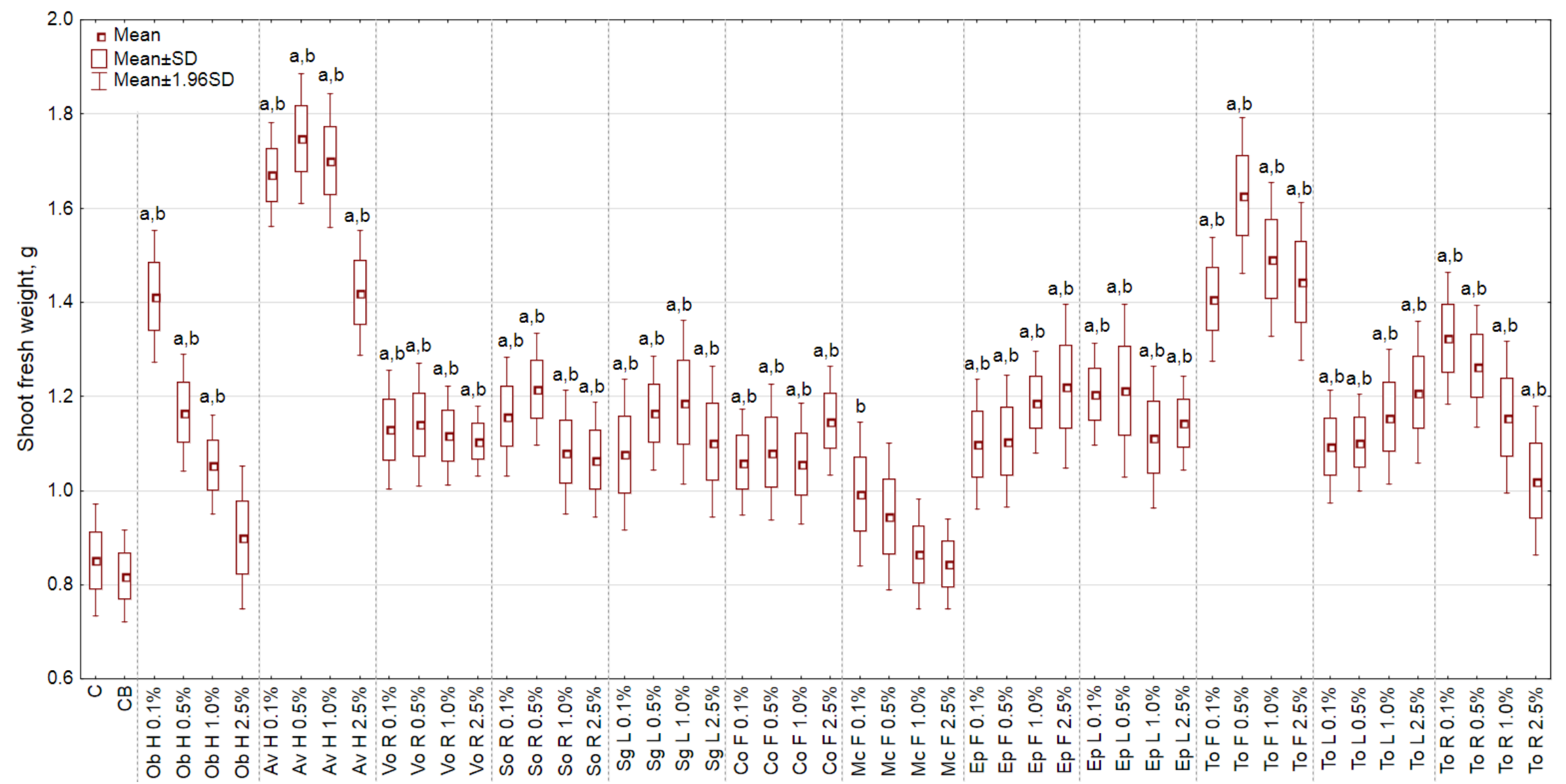

Figure 4. The effect of extracts on the fresh weight of shoots of white head cabbage seedlings. (a) Statistically significant differences ( $p<0.05)$ between control group (C) and extracts. (b) Statistically significant differences $(p<0.05)$ between commercial biostimulant $(\mathrm{CB})$ and extracts. Abbreviations as in Figure 2 . 


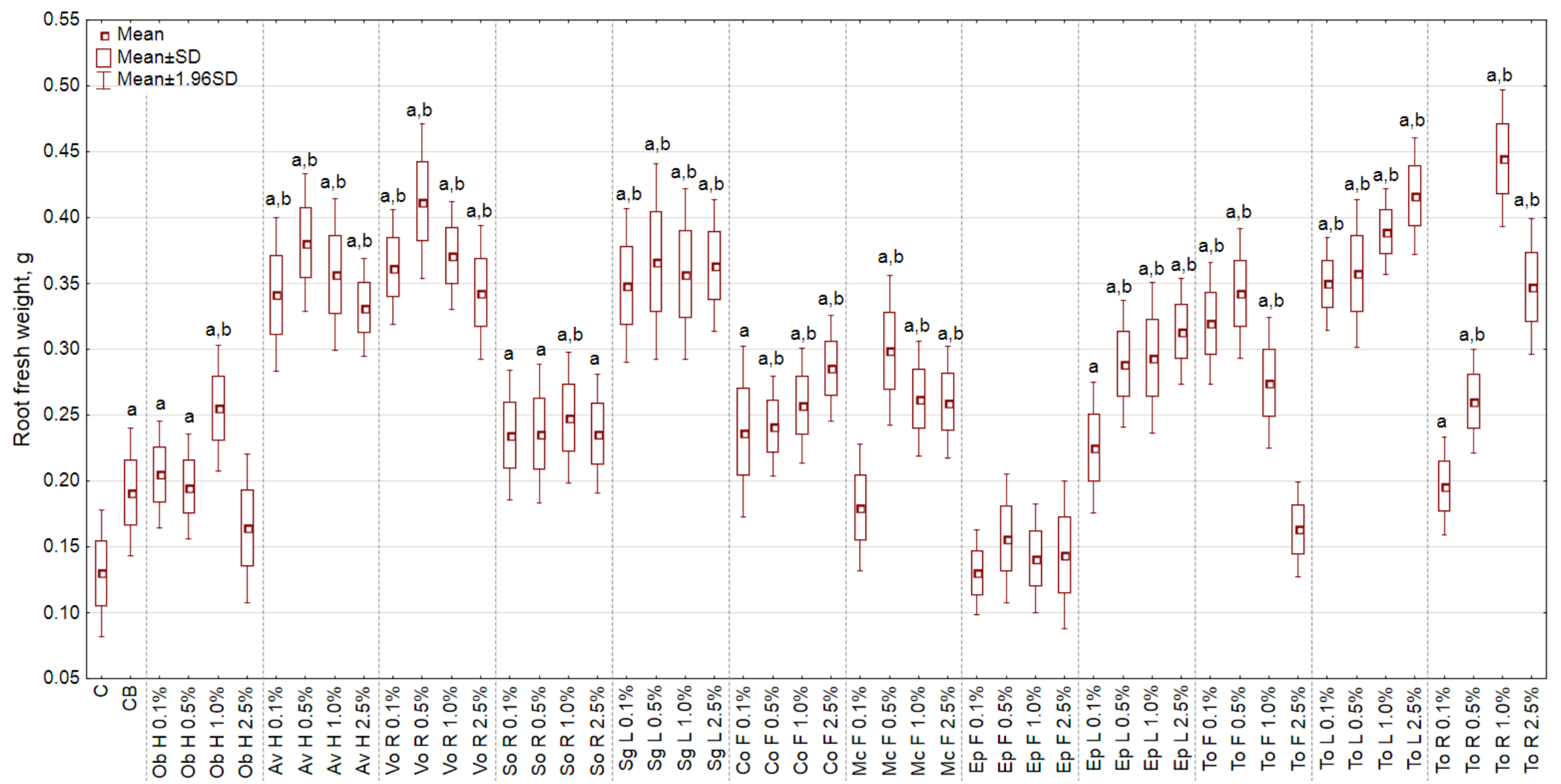

Figure 5. The effect of extracts on the fresh weight of roots of white head cabbage seedlings. (a) Statistically significant differences ( $p<0.05)$ between control group (C) and extracts. (b) Statistically significant differences $(p<0.05)$ between commercial biostimulant $(\mathrm{CB})$ and extracts. Abbreviations as in Figure 2 . 


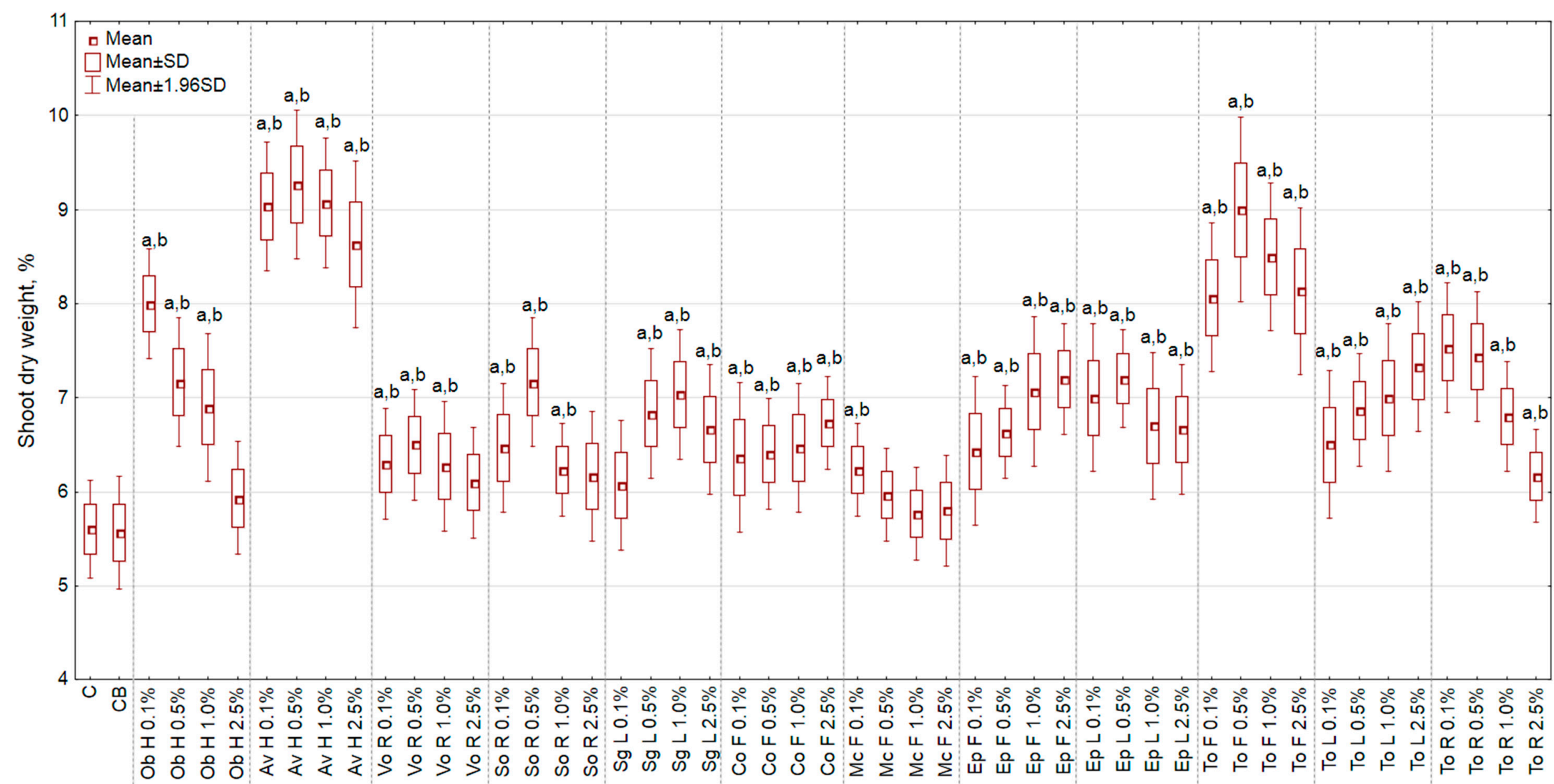

Figure 6. The effect of extracts on the dry weight of shoots of white head cabbage seedlings. (a) Statistically significant differences $(p<0.05)$ between control group (C) and extracts. (b) Statistically significant differences $(p<0.05)$ between commercial biostimulant $(\mathrm{CB})$ and extracts. Abbreviations as in Figure 2 . 


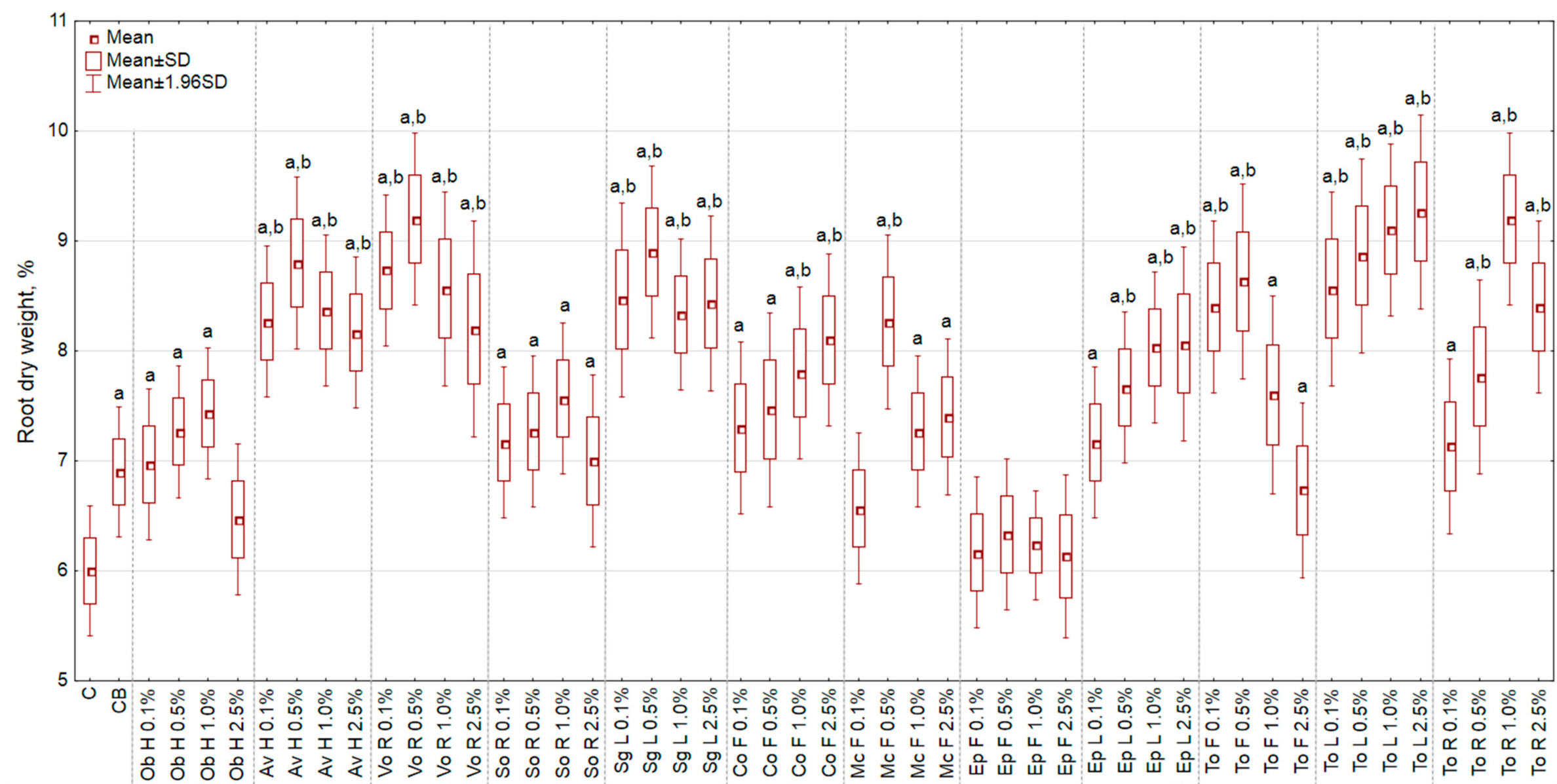

Figure 7. The effect of extracts on the dry weight of roots of white head cabbage seedlings. (a) Statistically significant differences $(p<0.05)$ between control group (C) and extracts. (b) Statistically significant differences $(p<0.05)$ between commercial biostimulant $(\mathrm{CB})$ and extracts. Abbreviations as in Figure 2. 


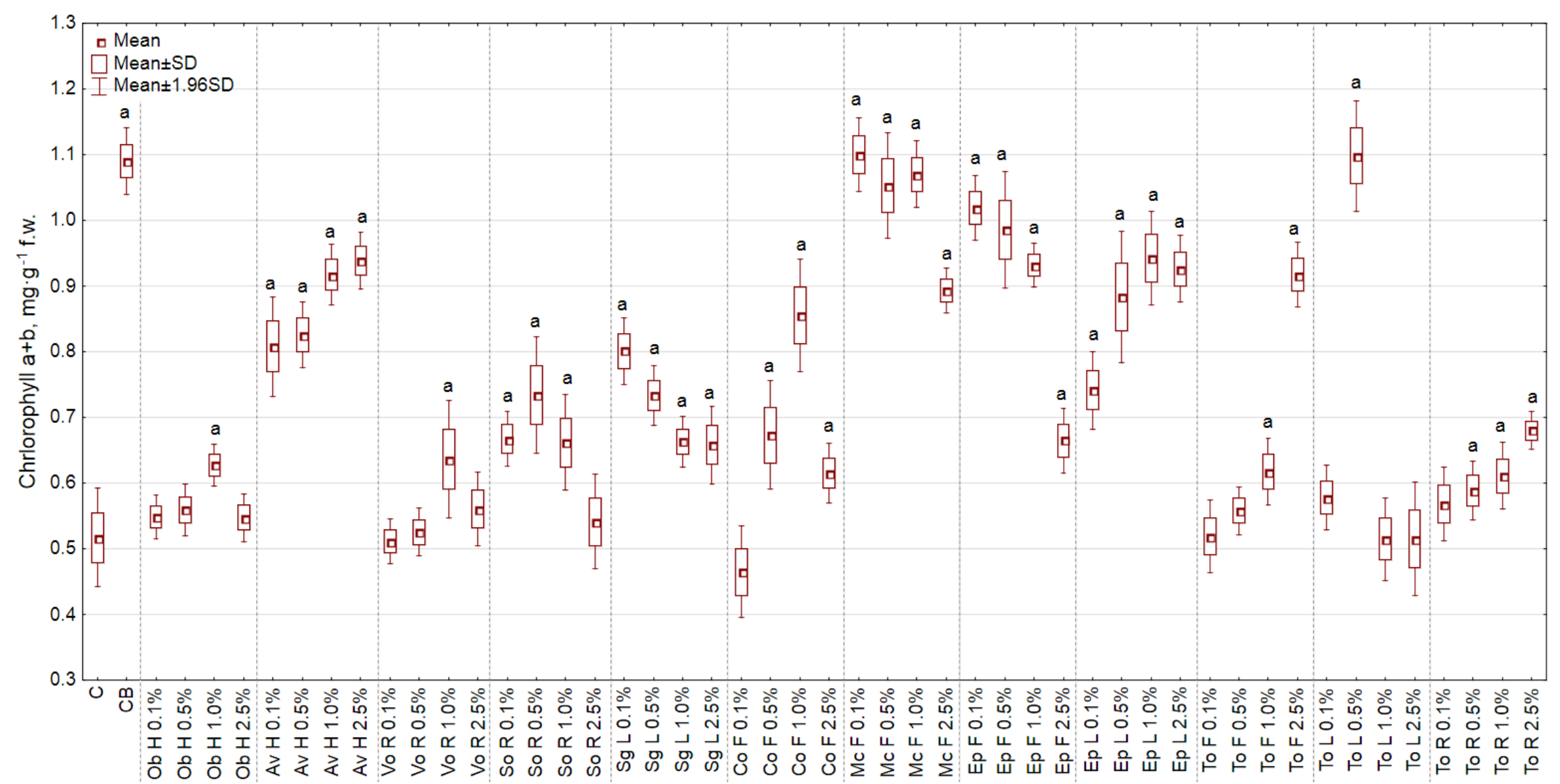

Figure 8. The effect of extracts on the content of chlorophyll $a+b$ in white head cabbage seedlings. (a) Satistically significant differences ( $p<0.05$ ) between control group $(C)$ and extracts. (b) Satistically significant differences $(p<0.05)$ between commercial biostimulant $(\mathrm{CB})$ and extracts. Abbreviations as in Figure 2. 
As in the case of chlorophyll, also the content of carotenoids in leaves was higher than in the control group (Figure 9). The meaningful differences were recorder for $1.0 \% \mathrm{Mc} F(87.1 \%$ more than in C) and commercial product ( $82.0 \%$ more than in C). The lowest amount of carotenoids was noted in groups treated with $0.1 \%$ Co F ( $3.8 \%$ less than in C).

A SPAD meter was also used to determine the content of photosynthetic pigment in the tested seedlings (Figure 10). The SPAD technique is widely used for the rapid and nondestructive measurement of leaf chlorophyll concentrations. The highest greenness index of leaf was observed after application of CB (29.0\% higher than C), 1.0\% Mc F (29.8\% higher), 0.1\% Ep F (29.5\% higher), and 0.5\% To L (31.1\% higher). The lowest greenness index was recorded in the groups treated with the lowest concentrations of Vo R ( $0.9 \%$ more), Co F ( $0.7 \%$ more), and To F (1.9\% higher).

\subsection{The Effect of Extracts on the Content of Polyphenols}

It was found that the application of biostimulants mostly resulted in a significant decrease in the total phenolic content in cabbage shoots (Figure 11). The lowest content of polyphenols was noted in the groups treated with $0.1 \% \mathrm{Ob} \mathrm{H}$ (53.0\% less), 2.5\% Ep F (50.8\% less), and 2.5\% Ep L (47.9\% less). A significant difference was observed after the application of $0.5 \%$ Co F ( $27.7 \%$ more than in C) and commercial biostimulant ( $14.7 \%$ more).

\subsection{The Effect of Extracts on the Antioxidant Activity (DPPH, ABTS, FRAP)}

DPPH radical scavenging method enabled comparison of the antioxidant properties of different botanical extracts. This technique measures the overall antioxidant capacity in a sample due to low specificity for the detection of specific antioxidant components. As in the case of polyphenols, most of the biostimulants decreased the antioxidant activity (Figure 12a), for example, $0.1 \% \mathrm{Ob} \mathrm{H}(87.4 \%$ lower than in C), 2.5\% Ep F (83.7\% lower), and 2.5\% Ep L (80.5\% lower). The highest activity was noted in groups treated with $2.5 \%$ So R (105.7\% higher than in C and $82.7 \%$ than in $\mathrm{CB}$ ) and all concentrations of Co $\mathrm{F}(98.1 \%$ to $105.7 \%$ higher than in $\mathrm{C}$ and $76.0 \%$ to $82.7 \%$ higher than in $\mathrm{CB})$.

The antioxidant activity was also measured using ABTS assay which measures the relative ability of antioxidants to scavenge the $\mathrm{ABTS}^{\bullet+}$ generated in the aqueous phase. It was found that most of the extracts intensified this activity (Figure 12b). For example, in the group treated with $2.5 \%$ So R, an increase of $559.1 \%$ and $111.5 \%$, in comparison with $C$ and $C B$, respectively, was observed. Similar observation was made after application of $0.1 \%$ Ep F $(573.1 \%$ and $116.0 \%$ higher than $C$ and $C B$, respectively). The least stimulating proved to be $2.5 \%$ To $\mathrm{L}(17.5 \%$ and $73.6 \%$ lower than $\mathrm{C}$ and $\mathrm{CB}$, respectively).

The FRAP method, based on the reduction of colourless ferric complex $\left(\mathrm{Fe}^{3+}\right.$ tripyridyltriazine) to blue colored ferrous complex ( $\mathrm{Fe}^{2+}$ tripyridyltriazine) by the action of electron donating antioxidants at low $\mathrm{pH}$, was also assessed. In the majority, botanical extracts caused a reduction of this activity (Figure 12c). The lowest impact was observed for $0.1 \% \mathrm{Ob} \mathrm{H}(49.6 \%$ and $56.0 \%$ lower than $\mathrm{C}$ and CB) and $2.5 \% \mathrm{Ep} \mathrm{F}(39.9 \%$ and $47.5 \%$ lower), while the highest for $1.0 \% \mathrm{Co} \mathrm{F}$ (38.6\% and $21.0 \%$ higher than $\mathrm{C}$ and CB), $0.1 \%$ Mc F (50.7\% and 31.5\%), 0.5\% Ep L (34.6\% and $17.5 \%)$. 


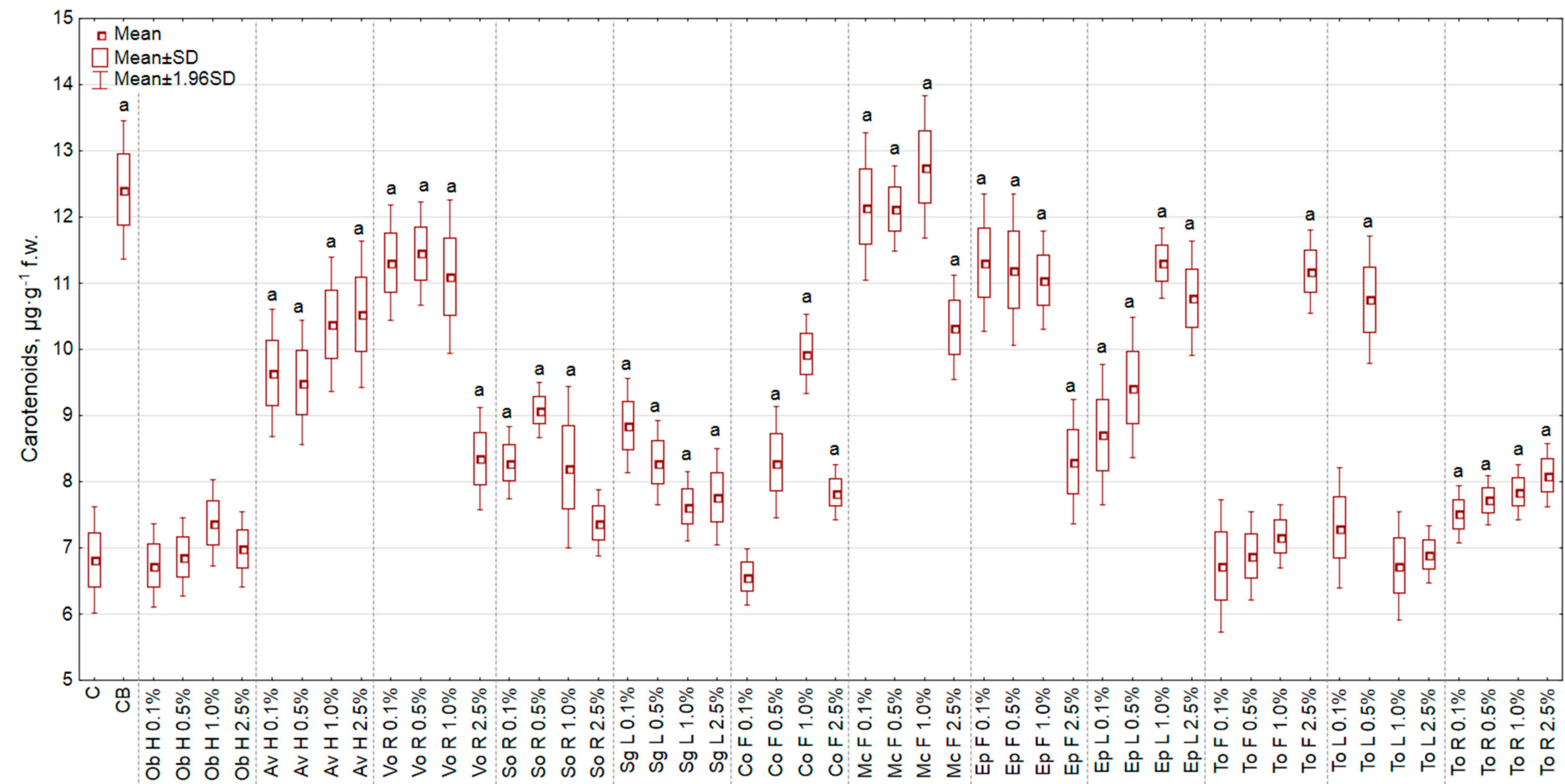

Figure 9. The effect of extracts on the content of carotenoids in white head cabbage seedlings. (a) Statistically significant differences $(p<0.05)$ between control group (C) and extracts. (b) Statistically significant differences $(p<0.05)$ between commercial biostimulant $(\mathrm{CB})$ and extracts. Abbreviations as in Figure 2. 


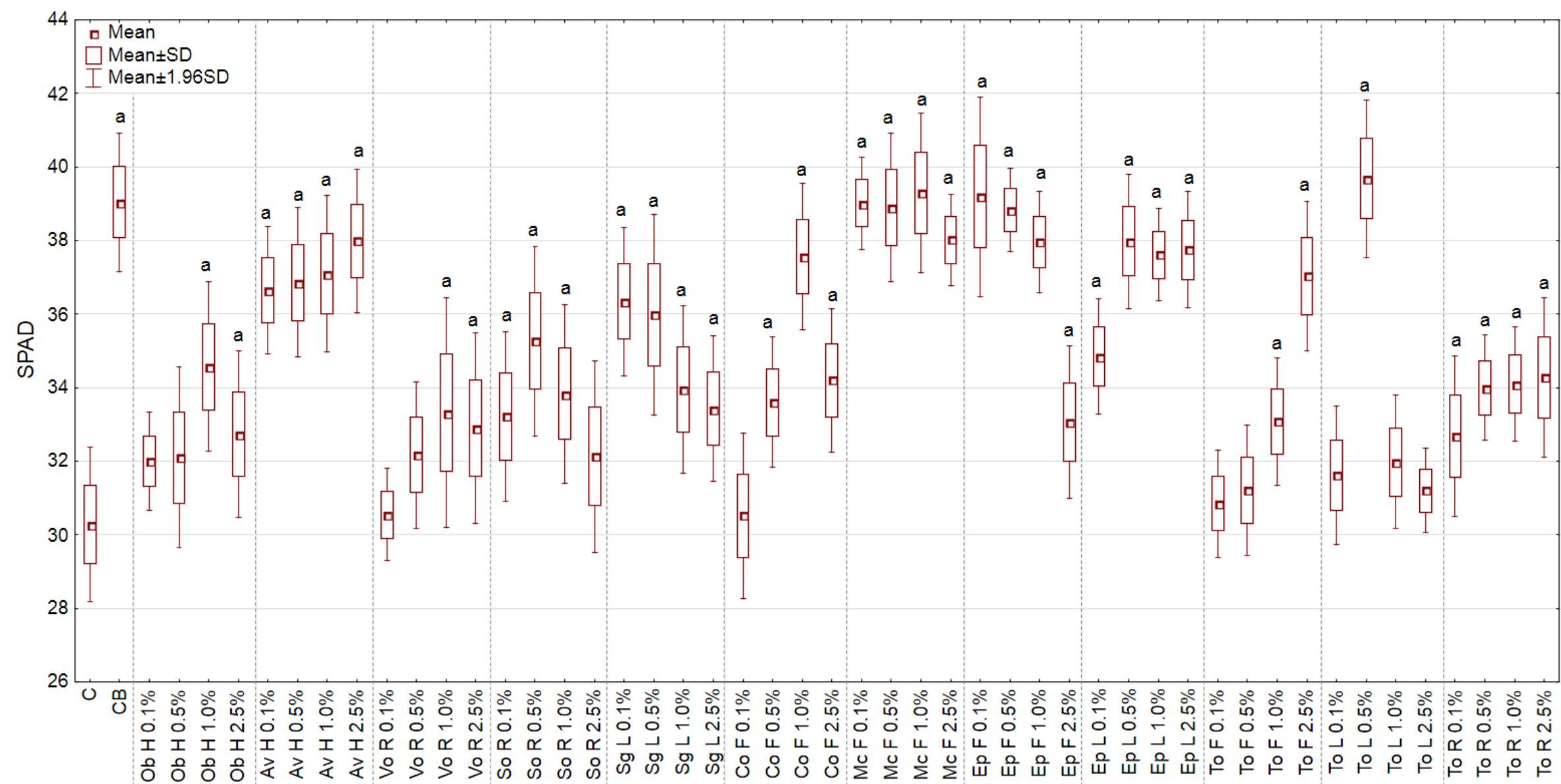

Figure 10. The effect of extracts on the greenness index of white head cabbage seedlings (SPAD). (a) Statistically significant differences $(p<0.05)$ between control group

(C) and extracts. (b) Statistically significant differences $(p<0.05)$ between commercial biostimulant $(\mathrm{CB})$ and extracts. Abbreviations as in Figure 2 . 


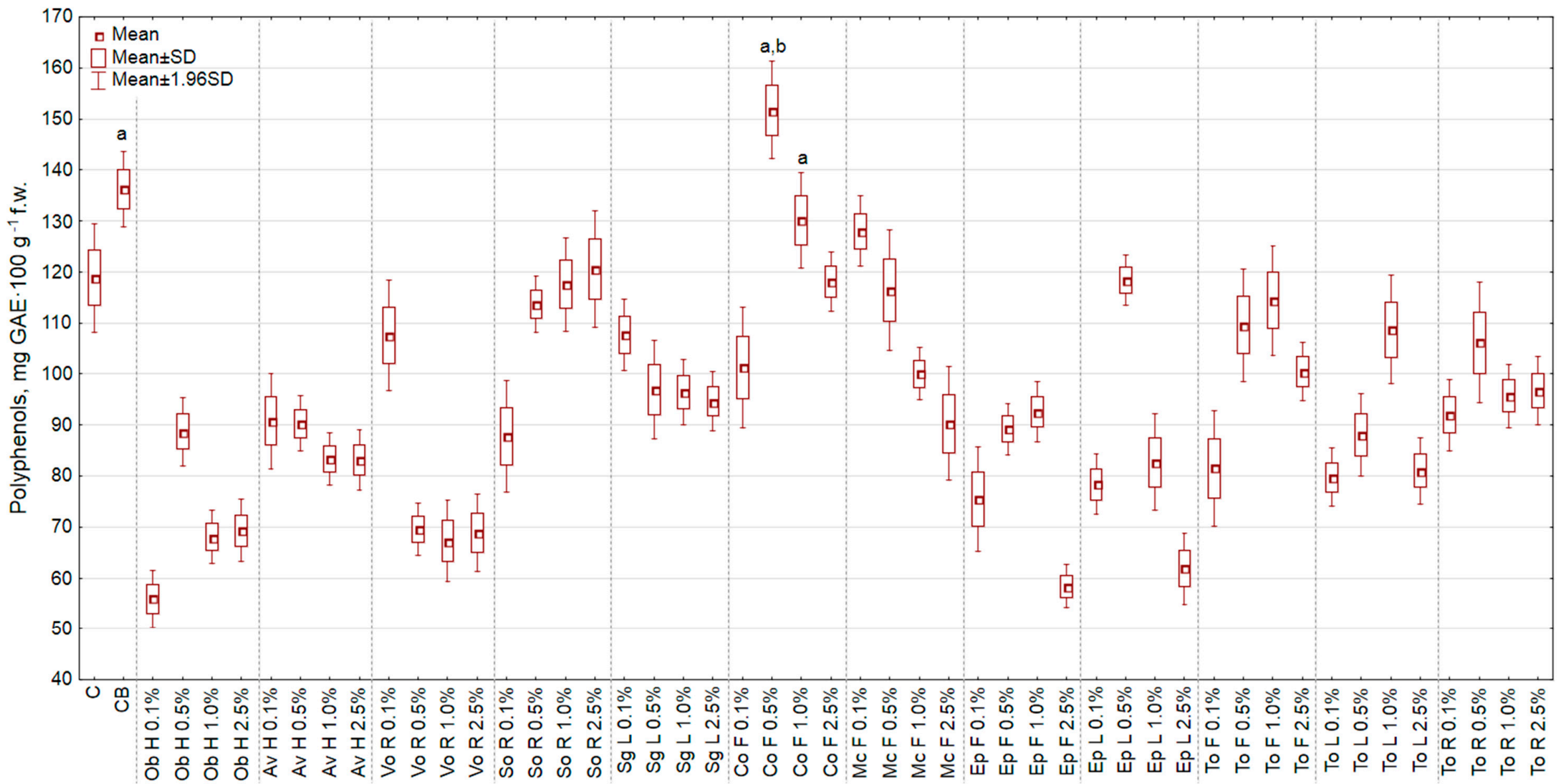

Figure 11. The effect of extracts on the content of polyphenols in white head cabbage seedlings. (a) Statistically significant differences ( $p<0.05)$ between control group (C) and extracts. (b) Statistically significant differences $(p<0.05)$ between commercial biostimulant $(\mathrm{CB})$ and extracts. Abbreviations as in Figure 2 . 


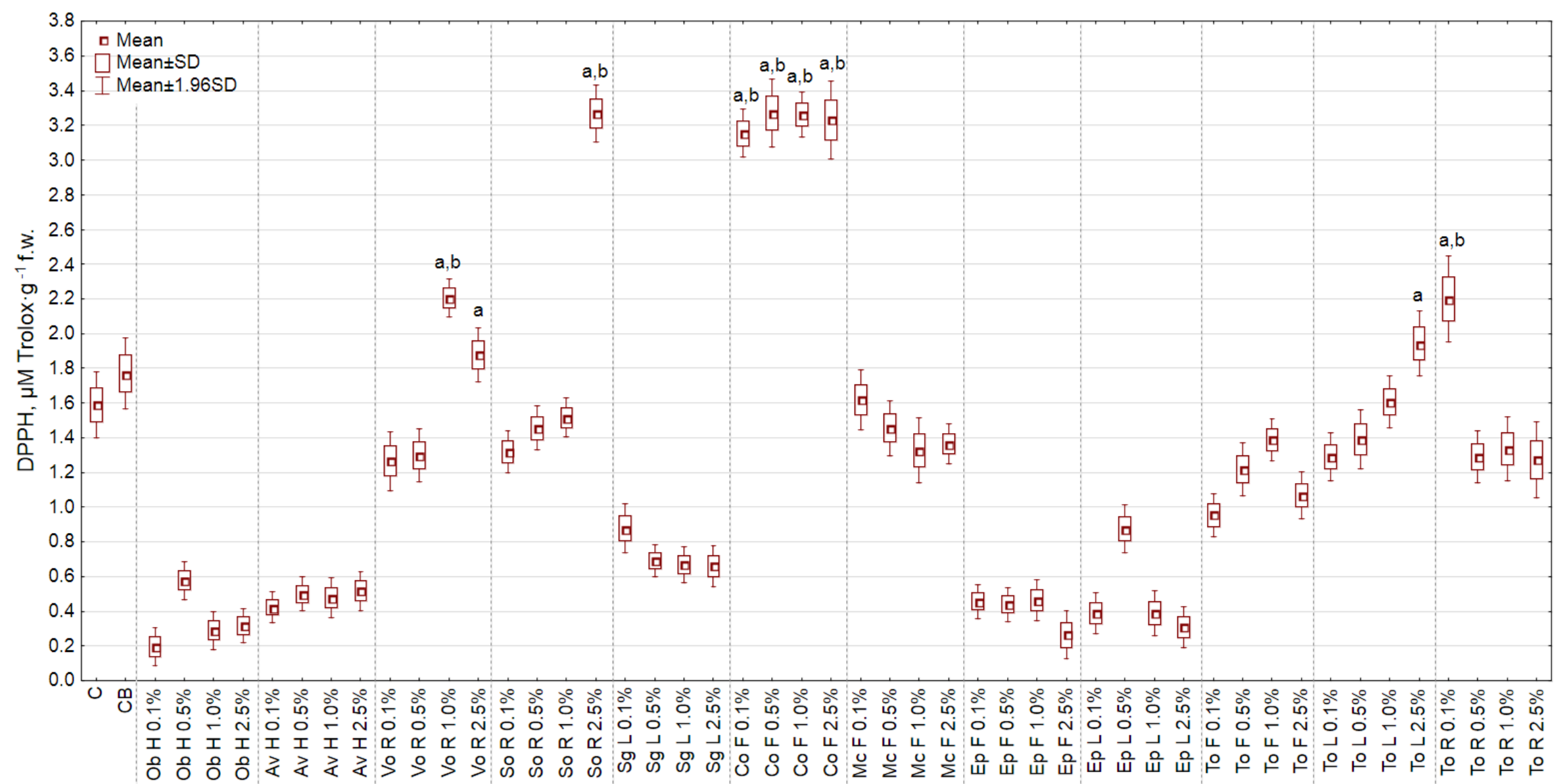

(a)

Figure 12. Cont. 


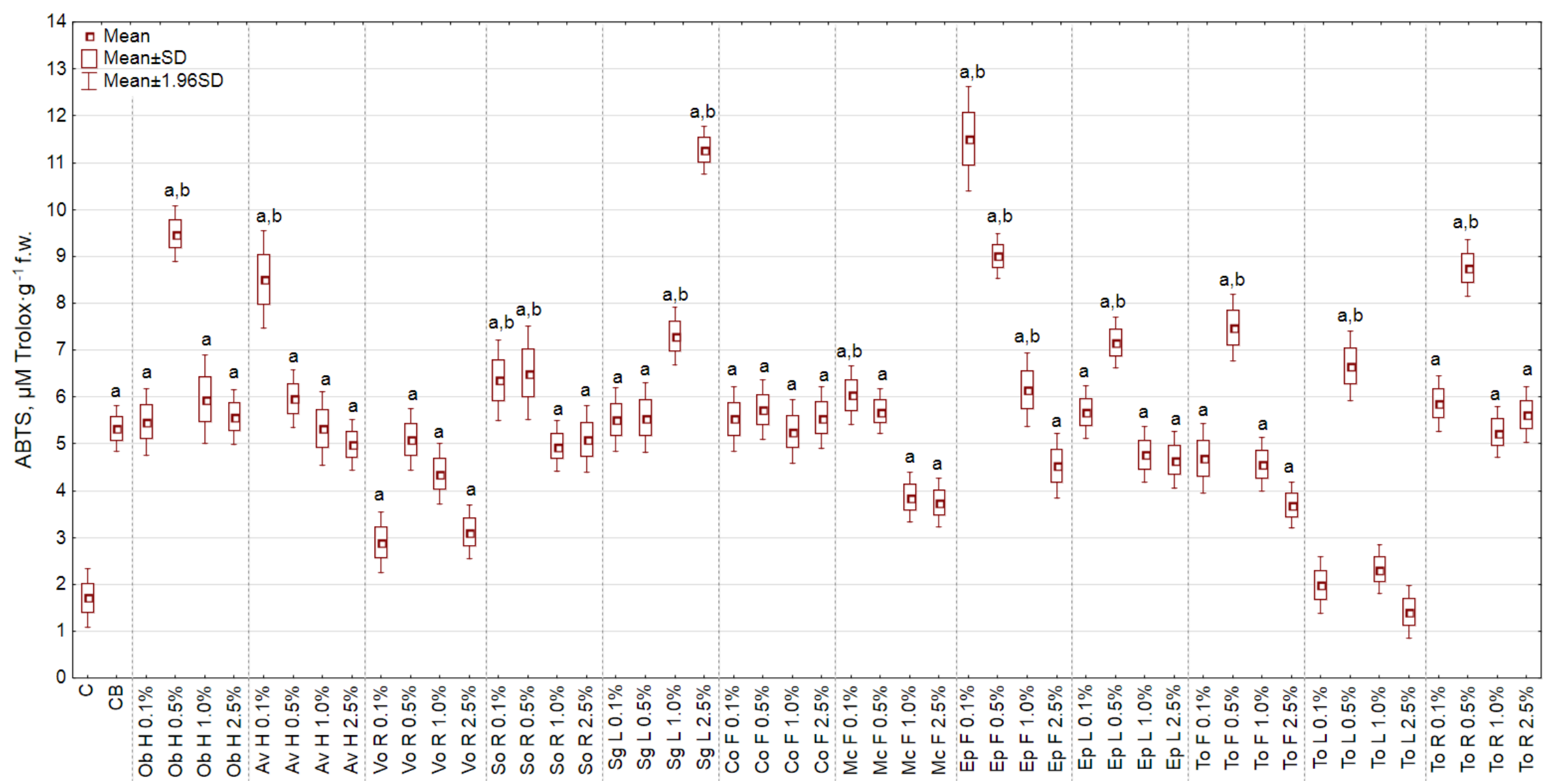

(b)

Figure 12. Cont. 


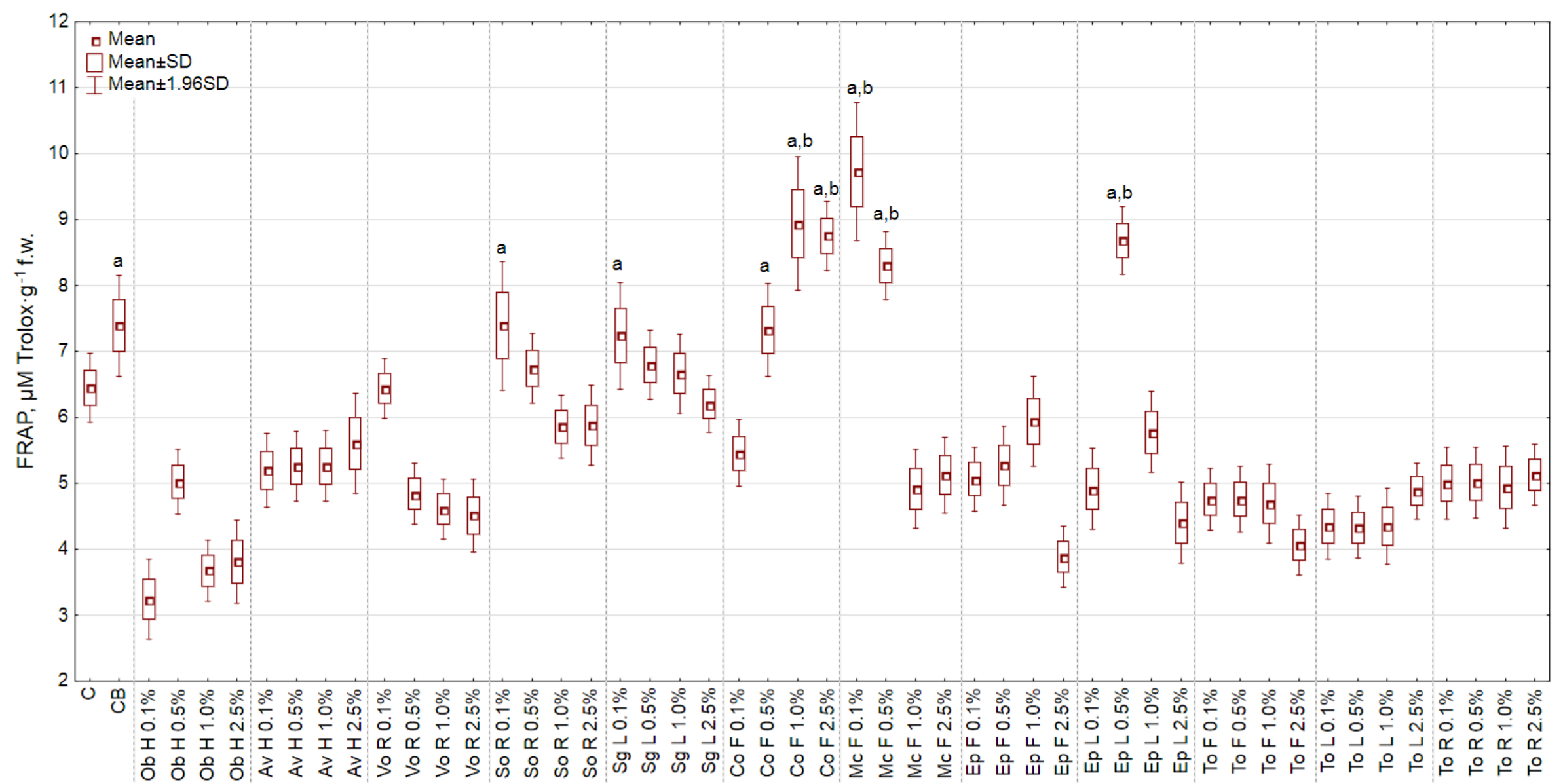

Figure 12. (a) The effect of extracts on the antioxidant activity (DPPH) of white head cabbage seedlings. (a) Statistically significant differences ( $p<0.05)$ between control group (C) and extracts. (b) Statistically significant differences $(p<0.05)$ between commercial biostimulant $(\mathrm{CB})$ and extracts. Abbreviations as in Figure 2. (b) The effect of extracts on the antioxidant activity (ABTS) of white head cabbage seedlings. (a) Statistically significant differences ( $p<0.05)$ between control group (C) and extracts. (b) Statistically significant differences $(p<0.05)$ between commercial biostimulant $(\mathrm{CB})$ and extracts. Abbreviations as in Figure 2 . (c) The effect of extracts on the antioxidant activity (FRAP) of white head cabbage seedlings. (a) Statistically significant differences $(p<0.05)$ between control group (C) and extracts. (b) Statistically significant differences $(p<0.05)$ between commercial biostimulant $(\mathrm{CB})$ and extracts. Abbreviations as in Figure 2. 


\section{Discussion}

A large number of existing studies have disclosed the beneficial effects of algal extracts application on plants, such as seed germination, increased crop yield and nutritional value, flower set and fruit production, raised resistance to stress (biotic and abiotic), and enhanced postharvest shelf-life of perishable products [3,20,27-32]. Currently, in comparison with seaweeds, much less is known regarding the activity of botanical biostimulants. These extracts, rich in active substances isolated from plants can be used in pharmaceutical and cosmetic products, such as food ingredients and plant protection products. There is an increasing number of reports about the possibility of using higher plants for the production of biostimulants (e.g., soy, carrot root, and blueberry fruits) [14,33-37]. On the Polish market, products based on, for example, chitosan (Biochikol 020 PC), grapefruit (Biosept $33 \mathrm{SL}$, Grevit 200 SL) and garlic (Bioczos BR) can also be found. The use of these types of products shows a promising perspective in the functional plant nutrition related to enhanced food quality parameters.

In this section we compared the results of the action of extracts produced from the proposed raw materials from the Asteraceae family with those that can be classified as "botanical extracts", however, due to the innovativeness of the approach there is still scarce literature data on the use of this type of products in horticulture and agriculture. The obtained results are promising as the use of natural biostimulants had a positive effect on the growth and development of white head cabbage seedlings. The plant growth parameters, such as plant length and weight, were significantly altered. The growth improvement in the plants can be due to the content of various growth-promoting compounds present in raw materials.

\subsection{The Application of Plant-Derived Biostimulants Increase the Shoot and Root Development}

Biostimulants of plant growth contain a wide range of molecules and due to their complexity, the composition is partly unknown, and it is difficult to verify which compounds are the most active [38]. The positive effects on plants are often ascribed to the synergistic action of the mixture of different compounds rather than a single one, thus, the isolation and study of the individual component from the solution can be unreliable [39]. Biostimulants exhibit their activity at very low concentrations [2]. Their mechanism of action is still unknown and under investigation [40]. For this reason, extracts should be categorized based on their physiological responses and action in the plants rather than on their composition. It is worth mentioning that biostimulants act on the metabolism of plants and their nutrient concentrations are negligible. Depending on their composition and desired results, this type of products can be applied directly to soil or as a foliar spray or in fertigation. An important element to consider is also the type of plant (e.g., leaf permeability) because biostimulants exert stimulatory activity only after penetration into the plant tissue. Furthermore, the environmental factors, dose and time of application can affect the biostimulants action which prevents generalization and utilization of the results in other species [39].

Our obtained results prove that botanical extracts, in addition to stimulating the growth of shoots, also affect the root system. This stimulatory activity may be closely related to the plant growth hormones which are mainly responsible for plant growth stimulation and increase the intensity of photosynthesis [41]. Auxins that may be present in the tested extracts are able to modify root formation and inhibit its elongation [32,39]. Extracts may also increase the nutrient uptake by roots, resulting in improved water and nutrient efficiency and enhanced general plant growth and vigor [32]. Moreover, auxins affect multiple physiological stages in the life cycle of plants and support proper cellular levels of active auxin which is significant for regulating all aspects of plant growth and development [42]. In addition, they are related to the nutrient partitioning in vegetative plant organs, as well as can be combined with the nutrient mobilization in reproductive organs. Cytokinins are also implicated in nutrient mobilization [32]. The foliar application of extracts also increased seedlings dry weight. This is a classic result of a biostimulatory activity that has the ability to modify plant metabolic processes in order to boost the potential growth benefits [14]. Thus, it is clear that most botanical extract components are very important for the plant growth by regulating many physiological processes. 


\subsubsection{The Effect of Extracts on the Length of Shoots}

Cabbage seedlings treated with extracts showed growth enhancement over control plants. A similar result was reached by scientists dealing with the impact of botanical extracts on plants. For instance, Abbas and Akladious (2013) [35] showed that carrot root extracts ( 25 and $50 \mathrm{~g} \cdot 100 \mathrm{~g}^{-1}$ ), obtained by blending the biomass with ethanol and water in a ratio of 1:1, improved the length of shoots of cowpea (Vigna sinensis L.). For example, 15 day old seedlings were 37.1\% higher for lower concentration and $29.1 \%$ for higher concentration in comparison with the nontreated control group. Amirkhani et al. (2016) [37] investigated the impact of seed coating formulations based on $10 \%$ suspension of soy flour in the cultivation of broccoli. The solid particulate filler was composed of a mixture of soy flour, cellulose fibers, and diatomaceous earth (SCD) in different proportions (00:00:100, 20:00:80, 30:00:70, 40:00:60, 50:00:50, 20:20:60, 30:20:50, 40:20:40, and 50:20:30). Then, homogenized in water, dried, ground to a fine particle size $(<106 \mathrm{~mm})$, and applied with rotary pan seed coating equipment. They observed that the length of 10 day old seedling, grown in a seed germinator, was significantly improved for all SCD coating treatments as compared with the control, e.g., by $21.3 \%$ and $38.3 \%$ for the composition of 50:20:30 and 20:20:60, respectively. They also conducted measurements after 30 days in the greenhouse tests and observed that plants treated with 40:20:40 and 50:00:50 composition were higher by $7.0 \%$ and $10.6 \%$. Hayat et al. (2018) [11] performed studies to identify the biostimulant activity of garlic extract. The aqueous solution was prepared by crushing $10 \mathrm{~g}$ of bulbs in a mortar and homogenization with $100 \mathrm{~mL}$ of distilled water. The obtained filtered supernatant was diluted to the concentration of 100 $\mu \mathrm{g} \cdot \mathrm{mL}^{-1}$ and applied to eggplant and pepper seedlings as foliar spray and as fertigation. Seeds were sown in plastic trays, and after emergence of true leaves, plants were transplanted into plastic pots (12 $\times 10 \mathrm{~cm}$ ) and grown in a glasshouse. After one week of post transplantation, the treatments of garlic biostimulant were applied three times in doses of 20 to $30 \mathrm{~mL}$ for each plant. The tests were conducted for 15 days. Distilled water was taken as a control. The results revealed positive effect of both applying methods on the length of chosen vegetables. In the case of pepper, foliar and root application of garlic extracts stimulated plant growth by $45.8 \%$ and $51.9 \%$, respectively. The positive response of eggplant growth was also noted as plants were longer by $38.2 \%$ and 33.3\%, respectively. Merwad (2018) [13] investigated the impact of Moringa oleifera extracts on pea plants in a field experiments carried out during the 2014 and 2015 growing seasons in Egypt. The biostimulant was prepared by mixing leaves $(20 \mathrm{~g})$ with $80 \%$ ethanol $(675 \mathrm{~mL})$, stirred with homogenizer, and filtered. Foliar application was done at 25,35 , and 45 days after planting at a rate of $0 \%, 1 \%, 2 \%, 3 \%$, and $4 \%$. All concentrations significantly increased the height of pea plants as compared to the control in both seasons, e.g., in the group treated with the highest concentration plants were longer by $49.0 \%$ in year 2014 and by $50.3 \%$ in year 2015 .

\subsubsection{The Effect of Extracts on the Length of Roots}

Botanical extracts showed also biostimulating activity on the length of roots. In the work of Abbas and Akladious (2013) [35], the carrot root extract also showed biostimulating effect on root length of cowpea seedlings. Plants treated with 25 and $50 \mathrm{~g} \cdot 100 \mathrm{~mL}^{-1}$ of biostimulant were longer by $59.7 \%$ and $30.2 \%$ as compared to nontreated plants, respectively. Amirkhani et al. (2016) [37] also demonstrated that all of applied formulations of soy flour, cellulose fibres, and diatomaceous earth, applied as seed coating products, improved the root growth of 10 day old broccoli seedlings, e.g., the formulations of 40:20:40 and 30:00:70 stimulated root length by $42.1 \%$ and $17.5 \%$ in comparison with the control, respectively. Hayat et al. (2018) [11] received similar results after application of a garlic extract. The pepper roots were longer by $37.3 \%$ and $26.9 \%$, and in the case of eggplant by $51.8 \%$ and $35.9 \%$ for foliar and fertigation methods as compared to C, respectively. In the study of Merwad (2018) [13], the use of all concentrations ( $1 \%$ to $4 \%$ ) of Moringa oleifera extracts on pea plants in field trials increased the root length, for example, in the season 2014 the $4 \%$ extract caused a growth by $103.4 \%$ while in the season 2015 by $101.9 \%$ In comparison with nontreated plants. 


\subsubsection{The Effect of Extracts on the Fresh Weight of Shoots}

Plant extracts are known to also enhance crop yield. Abbas and Akladious (2013) [35] showed that carrot root extract promoted seedlings fresh weight by $42.4 \%\left(25 \mathrm{~g} \cdot 100 \mathrm{~mL}^{-1}\right)$ and by $22.7 \%(50 \mathrm{~g} \cdot 100$ $\mathrm{mL}^{-1}$ ) in comparison with the control group. Ertani et al. (2013) [34] investigated the impact of the protein hydrolysate (EM), produced by a fully controlled enzymatic hydrolysis from alfa-alfa (Medicago sativa L.), on 14 days old Zea mays L. grown in 3 L pots containing an aerated complete culture solution. After 12 days, the protein hydrolysate $\left(1.0 \mathrm{mg} \cdot \mathrm{L}^{-1}\right)$ was added directly to the culture solution. It was observed that the fresh weight of leaves of plants supplied with EM was higher by $18.9 \%$ than the control. In the greenhouse experiments of Amirkhani et al. (2016) [37] the seed coating formulations based on soy flour, cellulose fibres, and diatomaceous earth increased the fresh weight of broccoli seedlings in all tested groups. The tested parameter ranged from 5.3\% more (for 00:00:100) to 35.9\% (for 50:00:50). In the work of Hayat et al. (2018) [11], the application of the garlic extract stimulated the shoot fresh weight of pepper by $40.0 \%$ and $41.7 \%$ and eggplant by $29.0 \%$ and $13.8 \%$ for foliar and fertigation treatments as compared to the control.

\subsubsection{The Effect of Extracts on the Fresh Weight of Roots}

The results of the fresh weight of roots lead to a similar conclusion as in the case of shoots of cabbage seedlings. In the study by Ertani et al. (2013) [34] the protein hydrolysate (EM) stimulated the root fresh weight by $77.3 \%$ of Zea mays L. as compared with C. Hayat et al. (2018) [11] stated that the garlic extract can also improve the root fresh weight of pepper by $63.2 \%$ and $58.8 \%$ and eggplant by $58.3 \%$ and $72.7 \%$ for foliar and fertigation methods, respectively.

\subsubsection{The Effect of Extracts on the Dry Weight of Shoots}

Our results confirm that botanic biostimulants are a good choice for the enhancement of the dry weight of plant shoots. Abbas and Akladious (2013) [35] demonstrated that carrot extract increased seedlings dry weight by $50.0 \%$ and $33.3 \%$ for concentrations 25 and $50 \mathrm{~g} \cdot 100 \mathrm{~mL}^{-1}$ than in C. Ertani et al. (2016) [14] investigated the influence of vegetal extracts derived from red grape (RGS), blueberry fruits (BB) (obtained by cool extraction), and hawthorn leaves (HN) (by controlled enzymatic hydrolysis) on Zea mays L. plant grown in three-liter pots containing an aerated complete culture solution. Twelve days after transplanting, plants were treated with $0.1 \mathrm{~mL} \cdot \mathrm{L}^{-1}$ or $1.0 \mathrm{~mL} \cdot \mathrm{L}^{-1}$ of biostimulant for $48 \mathrm{~h}$. The treated maize revealed increased leaf biomass with respect to untreated plants, e.g., $0.1 \mathrm{~mL} \cdot \mathrm{L}^{-1}$ $\mathrm{HN}$ and BB promoted the dry weight by $13.2 \%$, and $0.1 \mathrm{~mL} \cdot \mathrm{L}^{-1} \mathrm{RGS}$ by $15.8 \%$. Similar results were obtained in the work of Amirkhani et al. (2016) [37]. As in the case of the fresh weight, after application of SCD formulations on seed, they stimulated the content of dry weight from 9.0\% (for 00:00:100) to 43.3\% (for 40:20:40). Hayat et al. (2018) [11] observed analogous consequence for the dry weight as in the case of the fresh weight of shoot. The foliar and fertigation treatments with garlic extracts increased the content of dry weight by $54.4 \%$ and $47.9 \%$ for pepper, and by $38.2 \%$ and $26.2 \%$ for eggplant shoots as compared with C. Merwad (2018) [13] stated that Moringa oleifera extracts (1-4\%) increased the dry weight by $23.9 \%$ (for the lowest concentration) and by $68.4 \%$ (for the highest) in year 2014 . The same trend was found in the season 2015.

\subsubsection{The Effect of Extracts on the Dry Weight of Roots}

Our results also demonstrate the positive impact of bioproducts on the dry weight of roots. In the study by Ertani et al. (2016) [14], all concentrations of extracts from red grape, blueberry fruits, and hawthorn leaves did not show the biostimulating activity on Zea mays L. seedlings root dry weight. The results obtained by Hayat et al. (2018) [11] also proved that the garlic extract applied as foliar spray and fertigation increased the content of dry weight of roots by $93.1 \%$ and $75.8 \%$ for pepper, and by $56.3 \%$ and $42.8 \%$ for eggplant. Merwad (2018) [13] recorded the notable effects as growth of root 
dry weight ranging between $12.4 \%$ (for $1 \%$ extracts of Moringa oleifera) and $61.5 \%$ (for $4 \%$ extract) in 2014 and by $32.9 \%$ and $86.2 \%$ in 2015 , respectively.

\subsection{The Application of Plant-Derived Biostimulants Increased the Content of Photosynthetic Pigments in Cabbage Seedlings}

Photosynthesis is one of the primary processes of plant metabolism which is greatly impacted by environmental conditions [43]. Chlorophyll is a key component of photosynthesis required for the absorption of sunlight [44], and it occurs in chloroplasts as green pigments in all photosynthetic plant tissues [45]. On the other hand, carotenoids are also very important for plants because they protect the photosynthetic apparatus from light-mediated stress. They also work as accessory light-harvesting pigments, and traps light energy and pass it on to chlorophyll [45,46].

The Effect of Extracts on the Content of Chlorophyll and Carotenoids, and the Greenness Index of Leaf (SPAD)

This work proved that botanical extracts have a positive effect on the content of chlorophyll and carotenoids, as well as greenness index of leaves. Similar findings can be found in the work of Abbas and Akladious (2013) [35] where the application of carrot root extract, in the concentration $25 \mathrm{~g} \cdot 100 \mathrm{~mL}^{-1}$, enhanced the content of chlorophyll $a+b$ by $165.1 \%$ while the concentration of $50 \mathrm{~g} \cdot 100 \mathrm{~mL}^{-1}$ increased the content of carotenoids by $320.1 \%$ in comparison with a nontreated control. Ertani et al. (2016) [14] stated that all applied vegetal extracts (from hawthorn, red grape skin, and blueberry fruits) significantly affected the chlorophyll a and b content in maize plants. The highest amount of the total pigment was observed in the group treated with extract of red grape skin in the concentration $1.0 \mathrm{~mL} \cdot \mathrm{L}^{-1}$ (31.6\% more than in C). In an earlier work, Ertani et al. (2013) [34] investigated the impact of alfalfa plant-derived biostimulants on the SPAD index of Zea mays leaves. They noted that biostimulant increased the SPAD index by 14.3\%. Amirkhani et al. (2016) [37] showed that the application of SCD formulations (40:20:40) stimulated the greenness of broccoli leaves by 12.1\%. Moreover Hayat et al. (2018) [11] observed that the foliar application of garlic extracts increased the content of chlorophyll $a+b$ and carotenoids in pepper and eggplant seedlings. Merwad (2018) [13] found that Moringa oleifera extracts ( $1 \%$ to $4 \%$ ) can increase the content of chlorophyll $a+b$ by $54.8 \%$ and carotenoids by $103.8 \%$ (for the highest concentration), in year 2014. The same trend was found in the 2015 season. The increase in the photosynthetic pigment content may be a result of the reduction in chlorophyll degradation, which may be related with the presence of betaines in the extracts. Glycine betaine plays a crucial role in delaying the loss of photosynthetic activity through the inhibition of chlorophyll degradation during storage conditions in isolated chloroplasts [32]. As it was mentioned, the effect of botanical extracts can be the result of many interacting factors which are able to increase the content of pigments. Moreover, they may activate enzymes that are responsible for the regulation of photosynthetic carbon reduction and the protection of chloroplast from oxidative damage. Additionally, they may include compounds which serve a significant photoprotective role, by scavenging reactive oxygen species (e.g., carotenoids, $\beta$-carotene, zeaxanthin, tocopherols, and vitamin B) [35].

\subsection{The Application of Plant-Derived Biostimulants Influences the Content of Polyphenols and the Antioxidant Activity of Cabbage Seedlings}

Phenolic compounds, which are one of the most common groups of phytochemicals, are derivates of the shikimate, pentose phosphate, and phenylpropanoid pathways in plants. These secondary metabolites play a vital role in plant morphology and physiology (e.g., growth and reproduction) [47] and serve multiple functions during a wide range of abiotic stresses (e.g., high sunlight irradiance, drought, salinity, hot temperatures, and the scarcity of soil nutrients) [48]. For example, phenolic glucosides, hydroxycinnamic acid derivatives, and flavonoids are involved in the secondary cell wall thickening, causing the mechanical increase in reinforcement of tissues, thereby increasing the tolerance to drought. Moreover, polyphenol-induced strengthening of cell wall coupled with chemical-related 
functions, may also intensify endurance to oxidative stress (biotic and abiotic) [48]. Phenolic compounds may protect auxins from decarboxylation, thereby increasing the content of active forms of auxin which are necessary to stimulate or induce rooting [49-51]. Additionally, the number of $\mathrm{OH}$-groups and their position on the aromatic ring have an influence on the effectiveness of phenolic compounds $[50,52,53]$. High sunlight, in the absence of UV-irradiance, nitrogen or water deprivation, heat or cold, and root zone salinity rapidly increase the biosynthesis of polyphenols [48]. Numerous studies have demonstrated a strong correlation between the content of phenolic compounds and the antioxidant potential of fruits and vegetables [54,55]. The mechanism of action of plant secondary metabolites depends on many factors, for example, structure, physiological pathways, and interactions with the primary metabolism. The effects of biostimulants on plant secondary metabolism are not clear, but it was shown that they may increase the antioxidant potential of vegetables, flowers, and fruits [39]. Phenolic compounds have become an essential part of food preservation and contemporary health care, due to their antioxidant potential [53]. This group of phytochemicals displays a wide range of physiological properties, such as anti-inflammatory, anti-allergenic, antioxidant, anti-atherogenic, anti-microbial, cardioprotective, and vasodilatory effects. Their antioxidant activity is related to their ability to scavenge free radicals, donate hydrogen atoms or electrons, and chelate metal cations. The health benefits are associated with their absorption and metabolism which depends on their structure including their conjugation with other phenolics, degree of glycosylation or acylation, molecular size, and solubility. Plants are great sources of phenolic compounds, and have been researched as a source of natural antioxidants [47].

The Effect of Extracts on the Content of Polyphenols and the Antioxidant Activity (DPPH, ABTS, FRAP) of Cabbage Seedlings

In our research it was found that most of botanical extracts decreased the content of polyphenols and antioxidant activity (measured with DPPH and FRAP assay) but increased the antioxidant activity (ABTS assay). There are few science articles regarding the impact of botanical extracts on the content of polyphenols and antioxidant activity of cultivated plants. Ertani et al. (2013) [34] observed that the application of alfalfa plant-derived biostimulants decreased the level of phenols in Zea mays plants to values comparable to the ones measured in the control (by 19.6\%). As mentioned, polyphenols are not involved in the normal growth and development of plants [56], however, are directly involved (especially phenolic acids) in the response of plants to different types of stress [57]. For example, an improvement of phenylopropanoid metabolism and the quantity of phenolic compounds can be impacted by various environmental factors; the synthesis of isoflavones and several flavonoids is generated when plants are infected or injured, and also under low temperatures as well as low nutrient conditions [58-61]. Therefore, it can be assumed that botanical extracts strengthened plants (increased length and weight) and as a result seedlings did not need to produce polyphenols.

\section{Conclusions}

At the outcome of the study, it is concluded that foliar application of botanical extracts caused enhanced plant growth and development. The method enabled to increase bioavailability and preserve activity of compounds present in biomass. The length of shoots and roots, as well as wet and dry biomasses, after biostimulants applications was significantly different from the control. Taking into account biometric traits, positive effects were observed in the case of extract applications with lower concentration. On the other hand, the use of biostimulants increased the content of photosynthetic pigments, but in most cases decreased the content of polyphenols and antioxidant activity. The positive effects of extracts obtained in this study could be attributed to the presence of growth promoting substances in the botanical extracts. Considering the stimulatory effects on cabbage seedlings, Artemisia vulgaris, Valeriana officinalis, Solidago gigantea, and Taraxacum officinale, $0.5 \%$ extracts could be considered as an optimum concentration for foliar spray to obtain enhanced yield in organic agriculture. Additionally, extracts based on Echinacea purpurea could be used to treat unwanted plants in crops. Future work is needed to fully characterize the chemical composition of the applied 
natural biostimulants. Our subsequent studies should, therefore, involve molecular approaches in order to establish a concrete background for these processes and field trials to eliminate the gap between laboratory data on single biostimulants and field tests combined with fertilizers, which is very challenging and important. The gradual replacement of conventional chemicals with organic products, such as plant extracts, will bring significant benefits with regards to natural resources, as well as environmental and human health.

Author Contributions: K.G. designed and conducted the research, analyzed, obtained data, and wrote the paper; A.B. proposed the research question, reviewed and edited paper; I.M. analyzed obtained data and wrote the paper; P.P. prepared the graphics, analyzed obtained data and wrote the paper.

Funding: This work was supported by the Wrocław University of Environmental and Life Sciences (Poland) as the Ph.D. research program 'Innowacyjny Doktorat', no. D220/0008/18.

Conflicts of Interest: The authors declare no conflict of interest.

\section{References}

1. Rathore, S.S.; Chaudhary, D.R.; Boricha, G.N.; Ghosh, A.; Bhatt, B.P.; Zodape, S.T.; Patolia, J.S. Effect of seaweed extracts on the growth, yield and nutrient uptake of soybean (Glycine max) under rainfed conditions. S. Afr. J. Bot. 2009, 75, 351-355. [CrossRef]

2. du Jardin, P. Plant biostimulants: Definition, concept, main categories and regulation. Sci. Hortic. 2015, 196, 3-14. [CrossRef]

3. Calvo, P.; Nelson, L.; Kloepper, J.W. Agricultural uses of plant biostimulants. Plant Soil 2014, 383, 3-41. [CrossRef]

4. Sytar, O.; Hemmerich, I.; Zivcak, M.; Rauh, C.; Brestic, M. Comparative analysis of bioactive phenolic compounds composition from 26 medicinal plants. Saudi J. Biol. Sci. 2018, 25, 631-641. [CrossRef] [PubMed]

5. Barnes, J.; Anderson, L.A.; Gibbons, S.; Phillipson, J.D. Echinacea species (Echinacea angustifolia (DC.) Hell., Echinacea pallid (Nutt.) Nutt., Echinacea purpurea (L.) Moench): A review of their chemistry, pharmacology and clinical properties. J. Pharm. Pharmacol. 2005, 57, 929-954. [CrossRef] [PubMed]

6. Melguizo-Melguizo, D.; Diaz-de-Cerio, E.; Quirantes-Pine, R.; Svarc-Gajic, J.; Segura-Carretero, A. The potential of Artemisia vulgaris leaves as a source of antioxidant phenolic compounds. J. Funct. Foods 2014, 10, 192-200. [CrossRef]

7. Jan, N.; Andrabi, K.I.; John, R. Calendula officinalis-An important medicinal plant with potential biological properties. Proc. Indian Natl. Sci. Acad. 2017, 83, 769-787.

8. Michalak, I.; Chojnacka, K. Algal extracts: Technology and advances. Eng. Life Sci. 2014, 14, 581-591. [CrossRef]

9. Esclapez, M.D.; García-Pérez, J.V.; Mulet, A.; Cárcel, J.A. Ultrasound-assisted extraction of natural products. Food Eng. Rev. 2011, 3, 108. [CrossRef]

10. Knowles, A. Recent developments of safer formulations of agrochemicals. Environmentalist 2008, 28, 35-44. [CrossRef]

11. Hayat, S.; Ahmad, H.; Ali, M.; Hayat, K.; Khan, M.A.; Cheng, Z.H. Aqueous garlic extract as a plant biostimulant enhances physiology, improves crop quality and metabolite abundance, and primes the defense responses of receiver plants. Appl. Sci. 2018, 8, 1505. [CrossRef]

12. Martinez-Gil, A.M.; Garde-Cerdan, T.; Martinez, L.; Alonso, G.L.; Salinas, M.R. Effect of oak extract application to Verdejo grapevines on grape and wine aroma. J. Agric. Food Chem. 2011, 59, 3253-3263. [CrossRef] [PubMed]

13. Merwad, A.R.M.A. Using Moringa oleifera extract as biostimulant enhancing the growth, yield and nutrients accumulation of pea plants. J. Plant Nutr. 2018, 41, 425-431. [CrossRef]

14. Ertani, A.; Pizzeghello, D.; Francioso, O.; Tinti, A.; Nardi, S. Biological activity of vegetal extracts containing phenols on plant metabolism. Molecules 2016, 21, 205. [CrossRef] [PubMed]

15. Paradikovic, N.; Vinkovic, T.; Vrcek, I.V.; Zuntar, I.; Bojic, M.; Medic-Saric, M. Effect of natural biostimulants on yield and nutritional quality: An example of sweet yellow pepper (Capsicum annuum L.) plants. J. Sci. Food Agric. 2011, 91, 2146-2152. [PubMed] 
16. Saa, S.; Olivos-Del Rio, A.; Castro, S.; Brown, P.H. Foliar application of microbial and plant based biostimulants increases growth and potassium uptake in almond (Prunusdulcis [Mill.] D.A. Webb). Front. Plant Sci. 2015, 6, 1-9. [CrossRef] [PubMed]

17. Zhang, X. Who Guidelines on Good Agricultural and Collection Practices (GACP); World Health Organization: Geneva, Switzerland, 2003; pp. 15-16.

18. Mcdonnell, C.; Kumar, T.B. Ultrasound: A clean, green extraction technology of bioactives and contaminants. Compr. Anal. Chem. 2017. [CrossRef]

19. Maran, J.P.; Manikandan, S.; Nivetha, C.V.; Dinesh, R. Ultrasound assisted extraction of bioactive compounds from Nephelium lappaceum L. fruit peel using central composite face centered response surface design. Arab. J. Chem. 2017, 10, S1145-S1157. [CrossRef]

20. Godlewska, K.; Michalak, I.; Tuhy, Ł.; Chojnacka, K. Plant growth Biostimulants based on different methods of seaweed extraction with water. BioMed Res. Int. 2016, 2016, 1-11. [CrossRef]

21. Arnon, D.I. Copper enzymes in isolated chloroplasts. Polyphenoloxidase in Beta vulgaris. Plant Physiol. 1949, 24, 1-15.

22. Jałoszyński, K.; Figiel, A.; Wojdyło, A. Drying kinetics and antioxidant activity of oregano. Acta Agrophysica 2008, 11, 81-90.

23. Yen, G.C.; Chen, H.Y. Antioxidant activity of various tea extracts in relation to their antimutagenicity. J. Agric. Food Chem. 1995, 43, 27-32. [CrossRef]

24. Re, R.; Pellegrini, N.; Proteggente, A.; Pannala, A.; Yang, M.; Rice-Evans, C. Antioxidant activity applying an improved ABTS radical cation decolorization assay. Free Radic. Biol. Med. 1999, 26, 1231-1237. [CrossRef]

25. Almeida, M.M.B.; de Sousa, P.H.M.; Arriaga, Â.M.C.; do Prado, G.M.; de Carvalho Magalhães, C.E.; Maia, G.A.; de Lemos, T.L.G. Bioactive compounds and antioxidant activity of fresh exotic fruits from northeastern Brazil. Food Res. Int. 2011, 44, 2155-2159. [CrossRef]

26. Benzie, I.F.F.; Strain, J.J. The ferric reducing ability of plasma (FRAP) as a measure of "antioxidant power": The FRAP assay. Anal. Biochem. 1996, 239, 70-76. [CrossRef] [PubMed]

27. Ertani, A.; Francioso, O.; Tinti, A.; Schiavon, M.; Pizzeghello, D.; Nardi, S. Evaluation of seaweed extracts from Laminaria and Ascophyllum nodosum spp. As biostimulants in Zea mays L. using a combination of chemical, biochemical and morphological approaches. Front. Plant Sci. 2018, 9, 1-13. [CrossRef] [PubMed]

28. Di Filippo-Herrera, D.A.; Muñoz-Ochoa, M.; Hernández-Herrera, R.M.; Hernández-Carmona, G. Biostimulant activity of individual and blended seaweed extracts on the germination and growth of the mung bean. J. Plant Phycol. 2019, 31, 2025-2037. [CrossRef]

29. Godlewska, K.; Michalak, I.; Tuhy, Ł.; Chojnacka, K. The influence of pH of extracting water on the composition of seaweed extracts and their beneficial properties on Lepidium sativum. BioMed Res. Int. 2017. [CrossRef]

30. Michalak, I.; Tuhy, Ł.; Chojnacka, K. Seaweed extract by microwave assisted extraction as plant growth biostimulant. Open Chem. 2015, 13, 1183-1195. [CrossRef]

31. Kavipriya, R.; Dhanalakshmi, P.K.; Jayashree, S.; Thangaraju, N. Seaweed extract as a biostimulant for legume crop, green gram. J. Ecobiotechnology 2011, 3, 16-19.

32. Khan, W.; Rayirath, U.P.; Subramanian, S.; Jithesh, M.N.; Rayorath, P.; Hodges, D.M.; Critchley, A.T.; Craigie, J.S.; Norrie, J.; Prithiviraj, B. Seaweed extracts as biostimulants of plant growth and development. J. Plant Growth Regul. 2009, 28, 386-399. [CrossRef]

33. Pardo-García, A.I.; Martínez-Gil, A.M.; Cadahía, E.; Pardo, F.; Alonso, G.L.; Salinas, M.R. Oak extract application to grapevines as a plant biostimulant to increase wine polyphenols. Food Res. Int. 2014, 55, 150-160. [CrossRef]

34. Ertani, A.; Schiavon, M.; Muscolo, A.; Nardi, S. Alfalfa plant-derived biostimulant stimulate short-term growth of salt stressed Zea mays L. plants. Plant Soil 2013, 364, 145-158. [CrossRef]

35. Abbas, S.M.; Akladious, S.A. Application of carrot root extract induced salinity tolerance in cowpea (Vigna sinensis L.) seedlings. Pak. J. Bot. 2013, 45, 795-806.

36. Donno, D.; Beccaro, G.L.; Mellano, M.G.; Canterino, S.; Cerutti, A.K.; Bounous, G. Improving the nutritional value of kiwifruit with the application of agroindustry waste extracts. J. Appl. Bot. Food Qual. 2013, 86, 11-15.

37. Amirkhani, M.; Netravali, A.N.; Huang, W.; Taylor, A.G. Investigation of soy protein-based biostimulant seed coating for broccoli seedling and plant growth enhancement. Hort Sci. 2016, 51, 1121-1126. [CrossRef] 
38. Bulgari, R.; Franzoni, G.; Ferrante, A. Biostimulants application in horticultural crops under abiotic stress conditions. Agronomy 2019, 9, 306. [CrossRef]

39. Bulgari, R.; Cocetta, G.; Trivellini, A.; Vernieri, P.; Ferrante, A. Biostimulants and crop responses: A review. Biol. Agric. Hortic. 2015, 31, 1-17. [CrossRef]

40. Yakhin, O.I.; Lubyanov, A.A.; Yakhin, I.A.; Brown, P.H. Viostimulants in plant science: A global perspective. Front. Plant Sci. 2016, 7, 1-32.

41. Karthikeyan, K.; Shanmugam, M. Enhanced yield and quality in some banana varieties applied with commercially manufactured biostimulant Aquasap from sea plant Kappaphycus alvarezii. J. Agric. Sci. Technol. 2014, 4, 621-631.

42. Korasick, D.A.; Enders, T.A.; Strader, L.C. Auxin biosynthesis and storage forms. J. Exp. Bot. 2013, 64, 2541-2555. [CrossRef] [PubMed]

43. Kalaji, H.M.; Baba, W.; Gediga, K.; Goltsev, V.; Samborska, I.A.; Cetner, M.D.; Dimitrova, S.; Piszcz, U.; Bielecki, K.; Karmowska, K.; et al. Chlorophyll fluorescence as a tool for nutrient status identification in rapeseed plants. Photosynth. Res. 2018, 136, 329-343. [CrossRef] [PubMed]

44. Hörtensteinera, S.; Kräutler, B. Chlorophyll breakdown in higher plants. Biochem. Biophys. Acta (BBA) Bioenerg. 2011, 1807, 977-988. [CrossRef] [PubMed]

45. Dey, S.; Mazumder, P.B.; Paul, S.B. Effect of copper on growth and chlorophyll content in tea plants (Camellia sinensis (L.) O. Kuntze). IMPACT. Int. J. Res. Appl. Nat. Soc. Sci. 2014, 2, 223-230.

46. Young, A.J. The photoprotective role of carotenoids in higher plants. Physiol. Plant. 1991, 83, 702-708. [CrossRef]

47. Balasundram, N.; Sundram, K.; Samman, S. Phenolic compounds in plants and agri-industrial by-products: Antioxidant activity occurrence and potential uses. Food Chem. 2006, 99, 191-203. [CrossRef]

48. Di Ferdinando, M.; Brunetti, C.; Agati, G.; Tattini, M. Multiple functions of polyphenols in plants inhabiting unfavorable Mediterranean areas. Environ. Expr. Bot. 2014, 103, 107-116. [CrossRef]

49. Peer, W.A.; Murphy, A.S. Flavonoids and auxin transport: Modulators or regulators? Trends Plant Sci. 2007, 12, 556-563. [CrossRef]

50. De Klerk, G.-J.; Guan, H.; Huisman, P.; Marinova, S. Effects of phenolic compounds on adventitious root formation and oxidative decarboxylation of applied indoleacetic acid in Malus 'Jork 9'. Plant Growth Regul. 2011, 63, 175-185. [CrossRef]

51. Wilson, P.J.; Van Staden, J. Rhizocaline, rooting co-factors, and the concept of promoters and inhibitors of adventitious rooting-A review. Ann. Bot. 1990, 66, 479-490. [CrossRef]

52. Wu, H.C.; Du Toit, E.S.; Reinhardt, C.F.; Rimando, A.M.; Van der Kooy, F.; Meyer, J.J.M. The phenolic, 3,4-dihydroxybenzoic acid, is an endogenous regulator of rooting in Protea cynaroides. Plant Growth Regul. 2007, 52, 207-215. [CrossRef]

53. Gülçin, I. Antioxidant activity of food constituents: An overview. Arch. Toxicol. 2012, 86, 345-391. [CrossRef] [PubMed]

54. Reddy, C.V.K.; Sreeramulu, D.; Raghunath, M. Antioxidant activity of fresh and dry fruits commonly consumed in India. Food Res. Int. 2010, 43, 285-288. [CrossRef]

55. Sarawong, C.; Schoenlechner, R.; Sekiguchi, K.; Berghofer, E.; Ng, P.K.W. Effect of extrusion cooking on the physicochemical properties, resistant starch, phenolic content and antioxidant capacities of green banana flour. Food Chem. 2014, 143, 33-39. [CrossRef] [PubMed]

56. Papuc, C.; Goran, G.V.; Predescu, C.N.; Nicorescu, V.; Stefan, G. Plant polyphenols as antixodaitn and antibacterial agents for shelf-life extension of meat and meat products: Classification, structures, sources, and action mechanisms. Compr. Rev. Food Sci. Food Saf. 2017, 16, 1243-1268. [CrossRef]

57. Pandey, K.B.; Rizvi, S.I. Plant polyphenols as dietary antioxidants in human health and disease. Oxidative Med. Cell. Longev. 2009, 2, 270-278. [CrossRef] [PubMed]

58. Sakihama, Y.; Yamasaki, H. Lipid peroxidation induces by phenolics in cinjunction with aluminium ions. Biologia Plant. 2002, 45, 249-254. [CrossRef]

59. Grace, S.C.; Logan, B.A. Energy dissipation and radical scavening by the plant phenylopropanoid pathway. Philos. Trans. R. Soc. Lond. 2000, 355, 1499-1510. [CrossRef] [PubMed] 
60. Takahama, U.; Oniki, T. Flavonoid and some other phenolics as substrates of peroxidase: Physiological significance of the redox reactions. J. Plant Res. 2000, 113, 301-309. [CrossRef]

61. Michalak, A. Phenolic compounds and their antioxidant activity in plants growing under heavy metal stress. Pol. J. Environ. Stud. 2006, 15, 523-530. 